Research Article

\title{
Simplified Lateral Torsional Buckling (LTB) Analysis of Glass Fins with Continuous Lateral Restraints at the Tensioned Edge
}

\author{
Chiara Bedon (iD \\ University of Trieste, Department of Engineering and Architecture, Piazzale Europa 1, Trieste, Italy \\ Correspondence should be addressed to Chiara Bedon; chiara.bedon@dia.units.it
}

Received 31 December 2020; Accepted 10 March 2021; Published 25 March 2021

Academic Editor: Jose Renato de Sousa

Copyright (c) 2021 Chiara Bedon. This is an open access article distributed under the Creative Commons Attribution License, which permits unrestricted use, distribution, and reproduction in any medium, provided the original work is properly cited.

\begin{abstract}
Within multiple design challenges, the lateral torsional buckling (LTB) analysis and stability check of structural glass members is a well-known issue for design. Typical examples can be found not only in glass slabs with slender bracing members but also in facades and walls, where glass fins are used to brace the vertical panels against input pressures. Design loads such as wind suction give place to possible LTB of fins with LR at the tensioned edge and thus require dedicated tools. In the present investigation, the LTB analysis of structural glass fins that are intended to act as bracers for facade panels and restrained via continuous, flexible joints acting as lateral restraints (LRs) is addressed. Geometrically simplified but refined numerical models developed in Abaqus are used to perform a wide parametric study and validate the proposed analytical formulations. Special care is spent for the prediction of the elastic critical buckling moment with LRs, given that it represents the first fundamental parameter for buckling design. However, the LR stiffness and resistance on the one side and the geometrical/mechanical features of the LR glass members on the other side are mutually affected in the final LTB prediction. In the case of laminated glass (LG) members composed of two or more glass panels, moreover, further design challenges arise from the bonding level of the constituent layers. A simplified but rational analytical procedure is thus presented in this paper to support the development of a conservative and standardized LTB stability check for glass fins with LR at the tensioned edge.
\end{abstract}

\section{Introduction}

It is recognized that glass represents a structural material, with an increasing number of applications in buildings. Harmonized standards in support of safe structural design exist but are still under preparation [1-3] or do not include recommendations for the whole multitude of practical conditions. The last few years, in this regard, showed a huge spread of technical guidelines, codes of practice, and documents in support of designers [4-6], and research efforts are continuously in evolution.

Among others, the stability analysis of glass members is known to require dedicated calculation methods and verification procedures in order to achieve safe structural performances (Figure 1). Literature efforts can be found for several loading and boundary configurations of technical interest, including investigations on glass columns [7-11], beams [12-15], members under combined design loads
$[16,17]$, plates under compression or shear [18-20], and proposals of generalized design buckling procedures $[21,22]$. The use of equivalent thickness formulations for buckling purposes has also been addressed $[21,23,24]$. The buckling response of glass columns affected by variable input parameters is described in [25] with the support of the Monte Carlo simulation method, with nominal material properties [26] randomly modified.

The present study investigates the sensitivity of the elastic critical buckling moment for structural glass beams in lateral torsional buckling (LTB) as a major effect deriving from the presence of continuous lateral restraints (LRs) at the tensioned edge. The problem is typical of slender glass fins that are used to brace facade panels under wind suction. The presence of LRs, however, makes the LTB response markedly different from laterally unrestrained (LU) members. The current analytical study is first developed for fully monolithic LR members in LTB. The effects of geometrical 


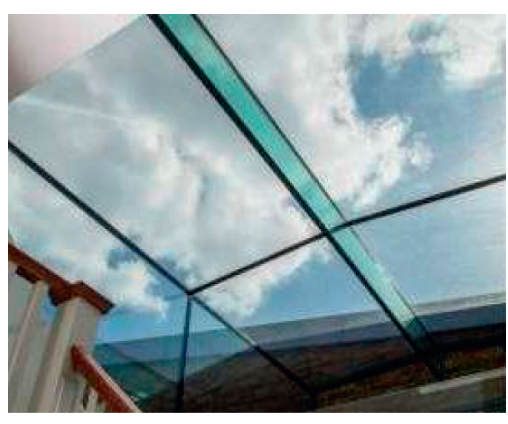

(a)

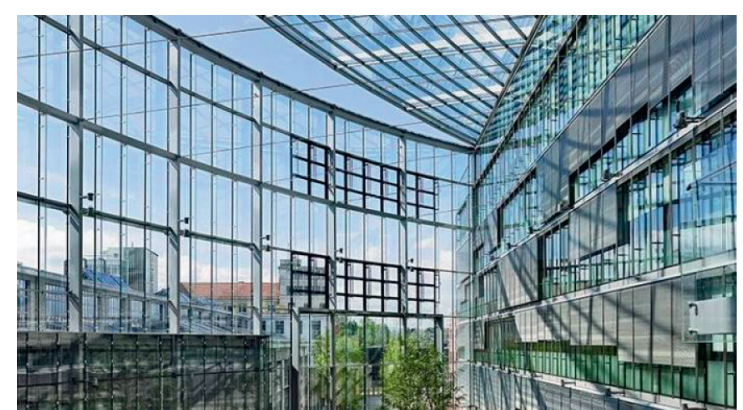

(b)

FIgURE 1: Structural glass used to brace roofs and facade panels .

parameters and LR shear stiffness are explored in terms of elastic critical moment, giving evidence of the expected magnification factor as a function of the input properties of the system to verify. Later on, the analysis is extended to laminated glass (LG) elements of typical use in practice, where two or more glass layers are bonded together, but the viscoelastic behaviour of interlayers makes the LTB analysis of the so-assembled composite sections even more complex. As shown, the solution of the governing mathematical problem for LR members in LTB is rather complex due to a mutual influence of multiple parameters. Besides, simple formulations of practical use are developed to capture the LTB trends of a given LR member. The proposed analytical approach is validated with the support of finite element (FE) numerical analyses [27]. Thanks to a linearized procedure, as shown, the proposed empirical equations can support an efficient and reliable estimation of the theoretical LTB capacity with LRs.

\section{State of the Art}

Design applications for glass fins and bracings are characterized by the presence of adhesive, mechanical, or combined joints that provide mechanical interaction to the linked components. In the case of fins and stiffeners such as in Figure 1, this results in the LTB analysis of glass members that are characterized by the presence of continuous or discrete lateral restraints (LRs) that can be variably designed.

Compared to LU members in LTB [21], the use of specific calculation methods for LR members is a basic need to account for the severe modifications in the LU structural behaviour. However, several input parameters are responsible for these behaviour modifications and make the definition of generalized approaches complex.

Studies that emphasize the beneficial effect of LRs for glass members in LTB can be found in [28-30]. An extended investigation and design proposal is presented in $[31,32]$ for LR members in LTB characterized by the presence of continuous LRs at the compressed edge (i.e., as in the case of a roof fin under sustained vertical loads). The same loading condition is further explored in [33] by taking into account the presence of discrete mechanical LRs. Experiments are finally reported in [34] for glass members with fully rigid discrete LR in LTB. In accordance with [31, 32] and Figure 2, the proposed research outcomes and design procedure for the LTB analysis of glass fins with flexible (or discrete [33]) LRs at the compressed edge show that the actual critical buckling moment $M_{\mathrm{cr}, R}^{(E)}$ of a given LR member progressively increases with the LR shear stiffness $k_{y}$ :

$$
M_{\mathrm{cr}, R}^{(E)}>M_{\mathrm{cr}}^{(E)}=\frac{\pi}{L} \sqrt{E J_{z} G J_{t}}
$$

or

$$
M_{\mathrm{cr}, R}^{(E)}=R_{M} M_{\mathrm{cr}}^{(E)}, \quad R_{M} \geq 1
$$

with $R_{\mathrm{M}}$ in Figure 2(b), an unknown magnification factor.

For a $b \times t$ monolithic member, $E$ and $G$ are Young's and shear moduli of glass, while $J_{z}$ is the flexural bending moment of the resisting section and $J_{t}$ is the torsional moment of inertia:

$$
\begin{gathered}
J_{z}=\frac{b t^{3}}{12} \\
J_{\mathrm{t}}=\frac{b t^{3}}{3} .
\end{gathered}
$$

2.1. Mathematical Model for Monolithic Members. The LTB analysis of LR glass fins with continuous flexible connections at the tensile edge is typical of practical applications in which a facade wall and the bracing fins are subjected to suction (Figure 1). Figure 3 schematizes the typical cross section of a LR glass fin with a continuous flexible joint. As far as the stiffness of the braced glass wall is disregarded, the joint can be efficiently represented in the form of distributed shear and rotational springs [31]. By increasing $k_{y}\left(k_{\theta}=0\right)$, the LTB response of the LR member progressively tends to increase compared to the base LU condition $\left(k_{y} \longrightarrow 0\right)$.

The monolithic glass fin has a rectangular $b \times t$ cross section and is simply supported at the ends of the buckling length $L$. Fork-end restraints for the fin enable possible outof-plane displacements due to the applied positive constant bending moment $M_{y}$ ("bottom" edge in tension), while the tensioned edge is variably restrained depending on $k_{y}$. As a starting reference for the current analysis, the LTB issue of glass fins with LR at the tensioned edge is explored first with the adaptation of past efforts from steel constructions and 

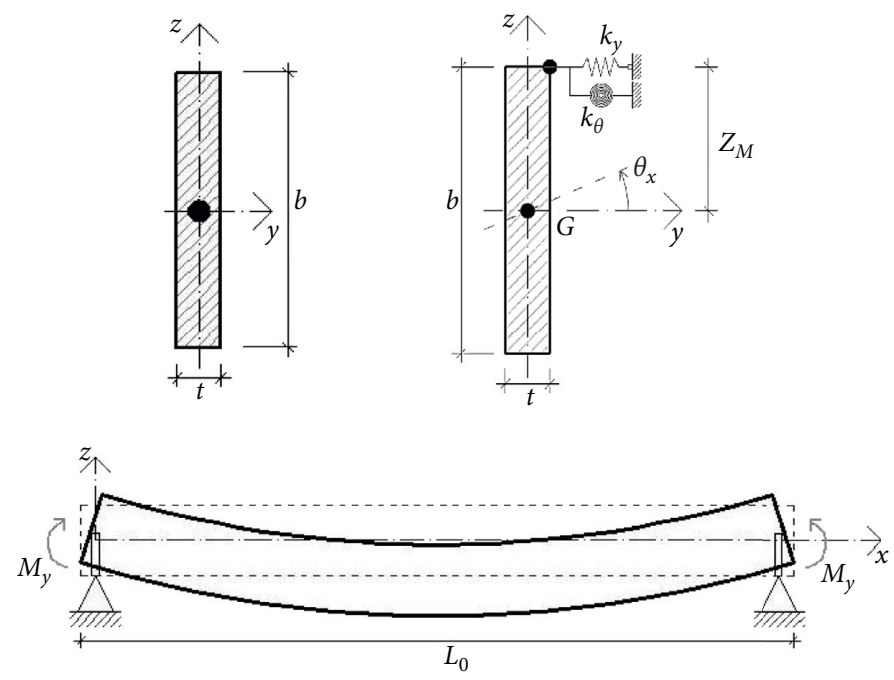

(a)

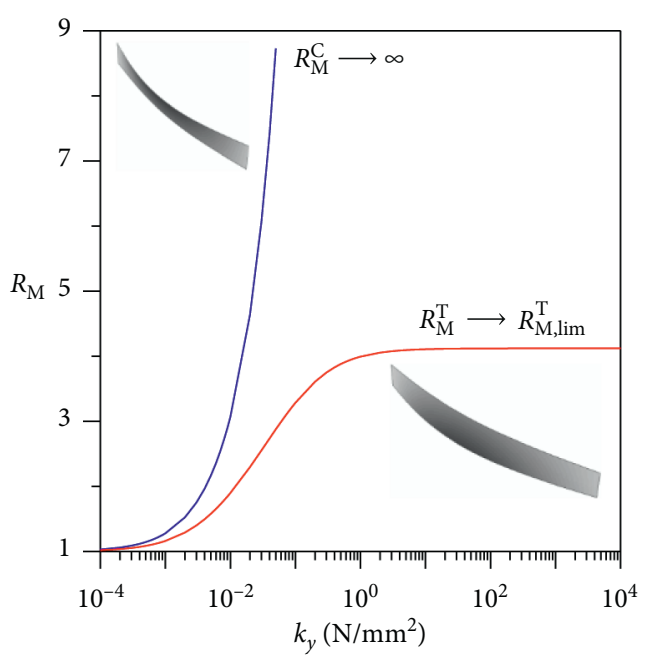

(b)

FIGURE 2: LR glass members in LTB [31]: (a) LU or LR member sections (compressive edge) with (b) magnification factor $R_{M}$ for the critical buckling moment as a function of $k_{y}$. "C" and " $T$ " denote, respectively, the compressed or tensioned edge with the LR.

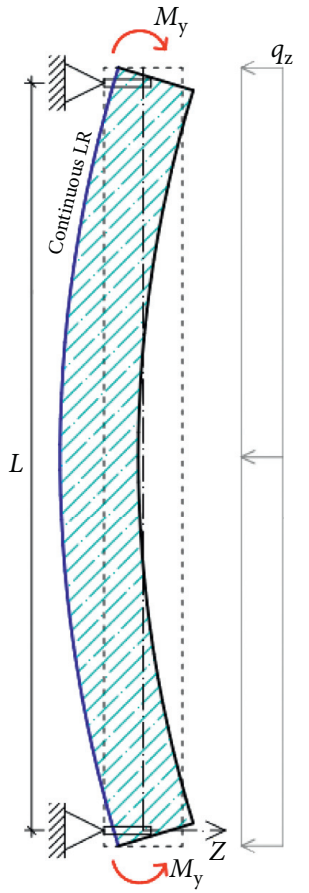

(a)

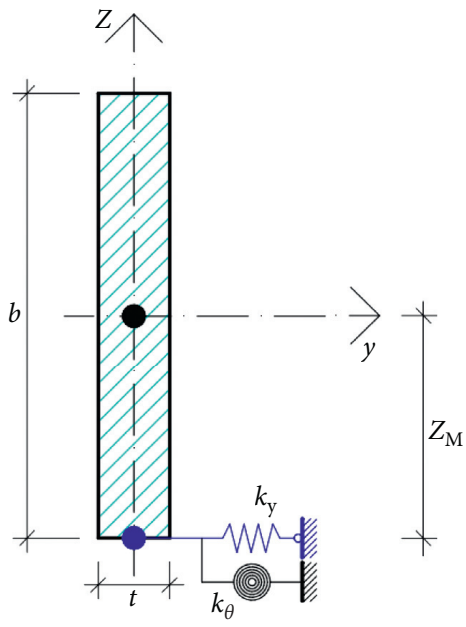

(b)

FIGURE 3: Reference mathematical model of a LR glass member in LTB, with tensioned edge restrained: (a) side view and (b) cross section. 
girders [35-38], especially [39-41]. Following [31, 32] and Figure 3, the LTB behaviour of the monolithic LR member can be derived from the solution of

$$
\begin{gathered}
E J_{z} \frac{\partial^{4} v}{\partial x^{4}}+k_{y} v+\left[\frac{\partial^{2}\left(\theta_{x} M_{y}\right)}{\partial x^{2}}-k_{y} z_{M} \theta_{x}\right]=0, \\
E J_{\omega} \frac{\partial^{4} \theta_{x}}{\partial x^{4}}-G J_{t} \frac{\partial^{2} \theta_{x}}{\partial x^{2}}+\theta_{x}\left(z_{q} q_{z}+k_{\theta}\right)+\frac{\partial^{2} v}{\partial x^{2}} M_{y} \\
-k_{y} z_{M}\left(v-z_{M} \theta_{x}\right)=0
\end{gathered}
$$

where

\section{$J_{\omega}$ is the warping constant}

$k_{y}$ represents the translational (shear) rigidity of the continuous elastic restraint, per unit of length, along the $y$-axis

$k_{\theta}$ is the rotational rigidity of the continuous elastic restraint, per unit of length, around the $x$-axis

$M_{y}$ is the applied bending moment $\left(M_{\mathrm{y}}>0\right.$ when the bottom flange is in tension)

$q_{z}$ represents a possible transversal distributed load

$z_{M}$ is the distance between the continuous LR and the $x$ axis

$z_{q}$ is the distance between the point of introduction of $q_{z}$ load and the $x$-axis

$v$ represents the vertical deflection of the member in the $z$-direction

$\theta_{x}$ is the rotation of the cross section around the longitudinal $x$-axis of the beam

In this paper, the closed-form solution of the differential system in equations (4a) and (4b) is further discussed in Sections 3 and 4 . It is first applied to a wide set of glass members with both monolithic or LG cross section and variable LR stiffness. Successively, empirical expressions of practical use are proposed to facilitate the prediction of the elastic critical buckling moment. The effect of input parameters is explored with the support of parametric calculations.

2.2. Laminated Glass Members. From a practical point of view, the use of LG sections that are obtained by bonding two or more glass panels represents the reference technical solution for safe structural glass design applications (Figure 4). In this regard, the literature offers a number of formulations and proposals for design that are based on the use of the simplified, equivalent thickness method and allow the analysis of approximated glass sections/members with a (flexural) monolithic thickness. Otherwise, the most important aspect for LTB considerations is represented by the need of dedicated calculations in terms of torsional stiffness of the so-defined equivalent monolithic glass sections, so as to include the viscoelastic properties of common interlayers on the final LTB performance indicators also [42]. The typical shear stiffness that is offered by the interlayers in use is in fact generally weak or anyway (for most of the design actions of technical interest) far away from the "fully rigid" bonding condition. It is thus required to first calculate the torsional contribution of the independent glass panels and then the equivalent term given by the interposed flexible torsional bonding.

According to the literature, the governing equations for LG members in LTB that are composed of two or three glass layers are given in Tables 1 and 2 (with $n_{\mathrm{g}}$ being the number of glass layers), with evidence of the equivalent flexural stiffness terms (Table 1) and of the equivalent torsional stiffness contribution due to partial bonding for the glass layers (Table 2). While the equivalent thickness concept can correctly capture the flexural rigidity of the composite LG section, as far as $G_{\text {int }}$ modifies, the trouble arises from the equivalent torsional term $J_{t}$, that is, largely affected by $G_{\text {int }}$ modifications and directly involves some variations in the theoretical critical buckling moment of the member in LTB.

The limit conditions for the equivalent expressions in Tables 1 and 2 are represented by the presence of a weak interlayer ("layered" limit, $G_{\text {int }} \longrightarrow 0$ ) or a rigid bond ("monolithic" limit, $G_{\text {int }} \longrightarrow \infty$ ). The effect of these limit configurations manifests in flexural and torsional parameters for a given LG composite section that progressively modify between the two reference values:

$$
\begin{aligned}
& J_{z}= \begin{cases}\longrightarrow J_{z, L}=\sum_{i=1}^{n_{g}} \frac{b t_{i}^{3}}{12}, & \text { layered limit, } \\
\longrightarrow J_{z, M}=\frac{b}{12}\left(\sum_{i=1}^{n_{g}} t_{i}\right)^{3}, & \text { monolithic limit, }\end{cases} \\
& J_{t}= \begin{cases}\longrightarrow J_{t, L}=\sum_{i=1}^{n_{g}} \frac{b t_{i}^{3}}{3}, & \text { layered limit, } \\
\longrightarrow J_{t, M}=\frac{b}{3}\left(\sum_{i=1}^{n_{g}} t_{i}\right)^{3}, & \text { monolithic limit. }\end{cases}
\end{aligned}
$$

For a practical comparison, let us consider a LG fin composed of three glass layers ( $t=10 \mathrm{~mm}$ each) and bonding foils with $t_{\text {int }}=0.76 \mathrm{~mm}$ thickness. The member has total dimensions $L=3000 \mathrm{~mm}$ and $b=300 \mathrm{~mm}$. The first step to address for the LTB analysis of the LG member is the calculation of the equivalent flexural and torsional contributions, under LU conditions, as a function of the actual interlayer stiffness $G_{\text {int }}$. The composite section characterization follows Tables 1 and 2. Figure 5 shows the variation of both flexural and torsional stiffness terms, as compared to the "layered" conditions ( $R_{\mathrm{FLEX}}$ and $R_{\mathrm{TOR}}$, respectively), as a function of $G_{\text {int }}$.

In Figure 5(a), it is possible to notice that the monolithic thickness $t_{\text {eq }}$ in Table 1 well captures the flexural properties of the multilayer member. However, compared to the composite model for torsion (Table 2), it disregards the actual capacity of the same section as far as $G_{\text {int }}$ modifies (Figure 5(b)). It turns out that the real torsional contribution of the LG member in LTB, based on $t_{\text {eq, }}$ could be highly 


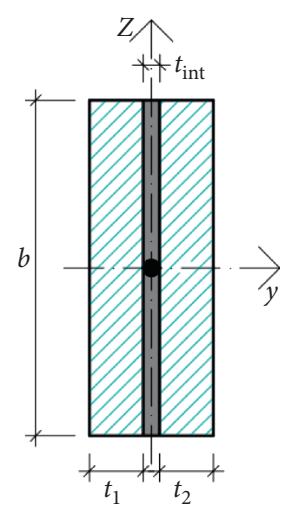

(a)

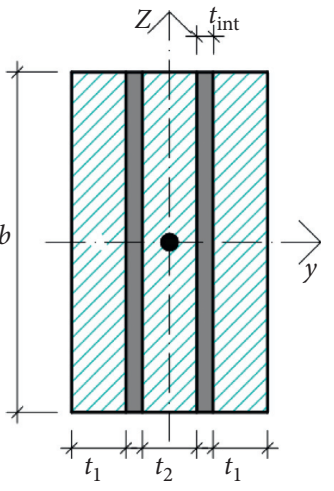

(b)

Figure 4: Example of LG sections with (a) two $\left(n_{\mathrm{g}}=2\right)$ or $(\mathrm{b})$ three $\left(n_{\mathrm{g}}=3\right)$ layers.

TABLE 1: Equivalent thickness definition for LG members in LTB [21], with $n_{\mathrm{g}}$ being the number of glass layers.

\begin{tabular}{lcr}
\hline & $n_{g}=2$ & $n_{g}=3$ \\
\hline$t_{\mathrm{eq}}$ & $\sqrt[3]{t_{1}^{3}+t_{2}^{3}+12 \Gamma_{\mathrm{b}} J_{\mathrm{s}}}$ & $\sqrt[3]{2 t_{1}^{3}+t_{2}^{3}+12 \Gamma_{b} J_{s}}$ \\
$\Gamma_{b}$ & $1 /\left(1+\pi^{2}\left(E t_{1} t_{2} t_{\text {int }} /\left(t_{1}+t_{2}\right) G_{\text {int }} L^{2}\right)\right)$ & $1 /\left(1+\pi^{2}\left(E t_{1} t_{\text {int }} / 4 G_{\text {int }} L^{2}\right)\right)$ \\
$J_{s}$ & $t_{1}\left(0.5 t_{1}+0.5 t_{\text {int }}\right)^{2}+t_{2}\left(0.5 t_{2}+0.5 t_{\text {int }}\right)^{2}$ & $t_{1}\left(0.5 t_{1}+0.5 t_{2}+t_{\text {int }}\right)^{2}$ \\
\hline
\end{tabular}

TABLE 2: Equivalent torsional stiffness definition for LG members in LTB [21], with $n_{\mathrm{g}}$ being the number of glass layers.

\begin{tabular}{lcr}
\hline & $n_{g}=2$ & $n_{g}=3$ \\
\hline$J_{\mathrm{t}}$ & $J_{\mathrm{t}, 1}+J_{\mathrm{t}, 2}+J_{\mathrm{t}, \mathrm{int}}$ & $2 J_{\mathrm{t}, 1}+J_{\mathrm{t}, 2}+J_{\mathrm{t}, \mathrm{int}}$ \\
$J_{t, i}$ & $J_{s, \mathrm{LT}}\left(1-\left(\tanh \left(0.5 \lambda_{\mathrm{LT}}^{3} b\right) / 0.5 \lambda_{\mathrm{LT}} b\right)\right)$ & $4 b\left(t_{1} t_{2} /\left(t_{1}+t_{2}\right)\right)\left(t_{1}+t_{2}+2 t_{\text {int }}\right)^{2}$ \\
$J_{t, \text { int }}$ & $4 b\left(t_{1} t_{2} /\left(t_{1}+t_{2}\right)\right)\left(0.5 t_{1}+0.5 t_{2}+t_{\text {int }}\right)^{2}$ & $\sqrt{\left(G_{\text {int }} / G\right)\left(\left(2 t_{1}+t_{2}\right) / 4 t_{1} t_{2} t_{\text {int }}\right)}$ \\
$J_{s, \mathrm{LT}}$ & $\sqrt{\left(G_{\text {int }} / G\right)\left(\left(t_{1}+t_{2}\right) / t_{1} t_{2} t_{\text {int }}\right)}$ & $\lambda_{\mathrm{LT}}$ \\
\hline
\end{tabular}

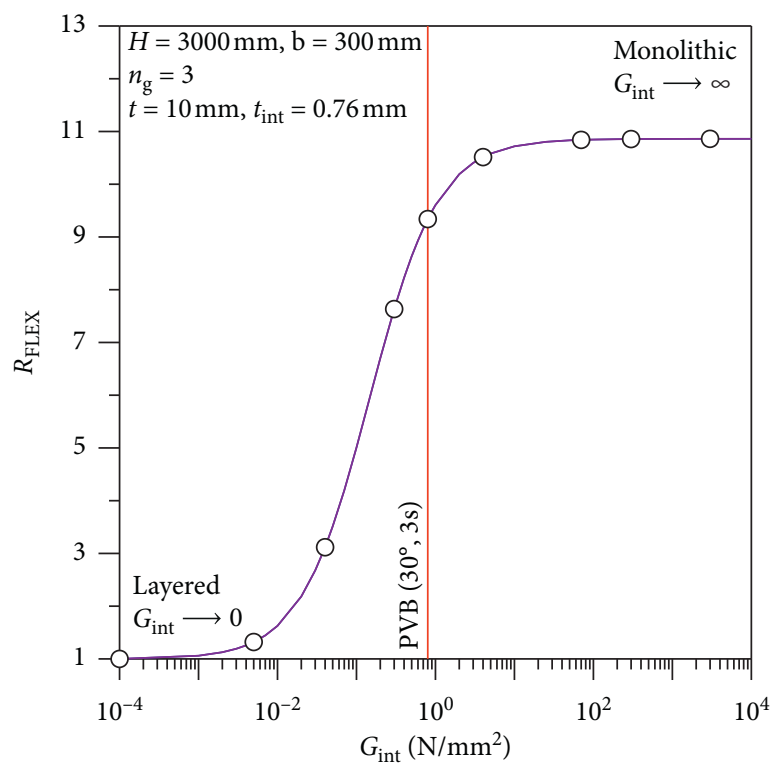

- Composite

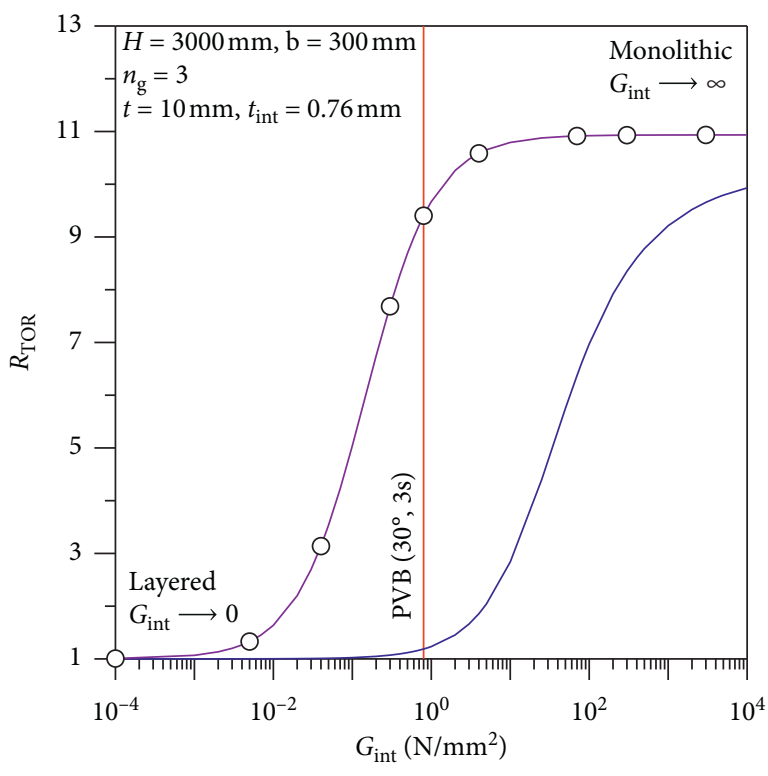

- Composite

(a)

(b)

FIgURE 5: Variation of (a) flexural and (b) torsional stiffness parameters for a LU laminated glass member based on the "composite" section approach (Tables 1 and 2) or on the flexural equivalent thickness (Table 1). 
overestimated, depending on the input parameters. Finally, Figure 5 extends to the $G_{\text {int }}$ range $10^{-4}-10^{4} \mathrm{MPa}$. This choice is derived from calculation purposes only and does not reflect real design applications for structural glass, where the common interlayers are characterized (for ordinary design conditions) by $G_{\text {int }}$ values that hardly exceed the order of $\approx 100 \mathrm{MPa}[3,4]$. As an example, the typical $G_{\text {int }}$ effect of PVB bonds under conventional wind loads is also emphasized (with $30^{\circ} \mathrm{C}$ reference operating temperature and $3 \mathrm{~s}$ load duration $[3,4])$.

\section{Elastic Critical Buckling Moment of Glass Members with LR at the Tensioned Edge}

3.1. Monolithic Members. As also discussed in [31, 32], the problem in Figure 3 requires the implementation of closedform solutions of suitable use for designers. However, the presence of a continuous LR is unavoidably associated to the definition of rather complex analytical models in which multiple parameters affect each other. Often, additionally, the derived closed-form solutions (when available) are obtained for limited loading/boundary conditions only. The alternative can take the form of more generalized and accurate (but computationally expensive) numerical models to develop case by case [33].

For the LTB analysis of glass members with flexible continuous LRs at the tensile edge, the first calculation approach should be focused on the definition of the critical buckling moment and shape. The structural benefit provided by continuous LRs, specifically, could be rationally quantified in the form of a magnification coefficient $R_{\mathrm{M}}{ }^{\mathrm{T}}$ as in equation (1b), with $0<k_{\mathrm{y}}<\infty$ and $k_{\theta}=0$, which could be extrapolated from the critical buckling moment definition:

$$
M_{\mathrm{cr}, R}^{(E)}=z_{M} k_{y}\left(\frac{L}{\pi}\right)^{2}-\sqrt{\left[E J_{z}\left(\frac{\pi}{L}\right)^{2}+k_{y}\left(\frac{L}{\pi}\right)^{2}\right]\left[E J_{\omega}\left(\frac{\pi}{L}\right)^{2}+G J_{t}+\left(z_{M}^{2} k_{y}+k_{\theta}\right)\left(\frac{L}{\pi}\right)^{2}\right]},
$$

where all the input parameters in equation (7) are defined from the differential system in equations (4a) and (4b).

It follows from equations (1a), (1b), and (7), mainly based on the input $k_{y}>0$, that the estimated $M_{\mathrm{cr}, R}^{(E)}$ could be significantly higher than Euler's critical moment of the same LU geometry. At the same time, however, the presence of LRs at the tensioned edge is characterized by well-known performance limit conditions in LTB, as also summarized in Figure 2(b). The design challenge of the present study, compared to past literature efforts on compressed edges with $\operatorname{LR}[31,32]$, is thus to quantify these tensioned edge LR effects on LTB and develop a practical calculation approach for design considerations.

The magnification factor $R_{M}^{T}$ unavoidably includes the effects derived from various parameters, such as the shear rigidity $k_{y}$ of the continuous joint, and also the beam aspect ratio, span, slenderness of the glass member (both monolithic or LG), and the position of the elastic restraints $\left(z_{M}\right)$. When $z_{M}=-b / 2$ as in the schematic drawing of Figure 4(b) and the elastic LR is applied at the tensioned edge, equations (1a), (1b), and (7) can be rearranged as

$$
R_{M}^{T}=\frac{-6 b L^{3} k_{y}+\sqrt{\left(3 b^{2} L^{2} k_{y}+16 E b t^{3}\right)\left(12 L^{4} k_{y}+97.4 E b t^{3}\right)}}{39.5 b t^{3} E},
$$

where $E=70 \mathrm{GPa}$ and $G 0.41 E$ for glass and

$$
1 \leq R_{M}^{T} \leq R_{M \text {.lim }}^{T} \text {. }
$$

As far as $k_{\mathrm{y}}$ modifies for a given geometry, $R_{M}^{T}$ progressively changes as in equations (8) and (9) and further affects the overall LTB response. The critical buckling shape, moreover, is limited in lateral displacements of the LR tensioned edge and can follow the qualitative trends in Figure 6.
The top limit condition associated to a "fully rigid" continuous LR is in fact given by

$$
R_{M, \lim }^{T}=R_{M}^{T}\left(k_{y} \longrightarrow \infty\right)
$$

and thus allows to calculate

$$
M_{\mathrm{cr}, R}^{(E)}=R_{M, \lim }^{T} M_{\mathrm{cr}}^{(E)} \longrightarrow M_{\mathrm{cr}, \infty} \approx \frac{G J_{t}}{b} .
$$

For a monolithic member, equation (11) can also be expressed as

$$
R_{M, \lim }^{T} \approx \frac{L}{2.4532 b}
$$

and allows to extrapolate the threshold limit $k_{y}$ that is associated to a "fully rigid" restraint (also, see Section 3.4). As far as $k_{y}$ increases in equation (8), the $R_{M}^{T}$ factor progressively tends to the limit value in equation (11). At the same time, it is also recognized that a given geometry to verify could receive a minimum benefit from the LR in use. Studies reported in [29-32] proved that the typical LR adhesive joints for structural glass applications are characterized by moderate shear stiffness, thus suggesting the need of a generalized calculation for $R_{M}^{T}$.

3.2. Discussion of Analytical Results. It is clear that the shear stiffness $k_{y}$ alone is not representative of a constant amplification factor for a given glass member object of study but can be further exploited by the flexural and torsional stiffness parameters of the member itself. Under the above conditions, the design calculation could first take advantage of the top limit value that the member object of study could ideally achieve. According to Figure 7, such a limit value can be easily expressed as a function of the $L / b$ ratio, while the effect of thickness $t$ can be disregarded. The collected analytical 


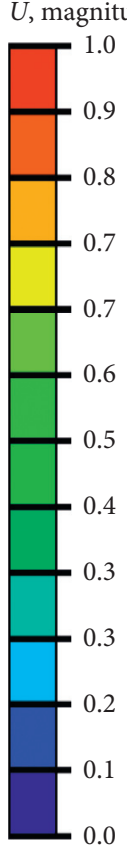

(a)

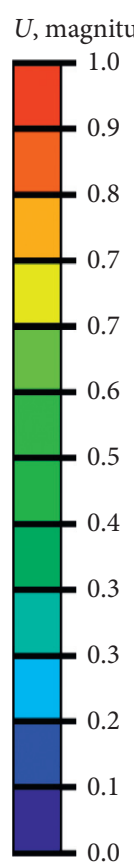

(b)
$U$, magnitude
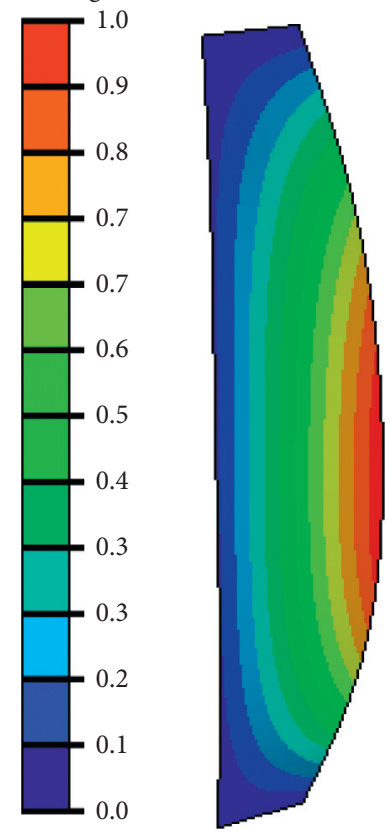

(c)

FIgURe 6: Qualitative critical buckling shapes and magnification factor $R_{M}^{T}$ for a monolithic fin with continuous LR at the tensioned edge (Abaqus/Standard) as a function of $k_{y}$ (with $k_{\theta}=0$ ): (a) $k_{y} \longrightarrow 0$ and $R_{M}^{T}=1$, (b) $0<k_{y}<\infty$ and $1<R_{M}^{T}<R_{M, l i m}^{T}$, and (c) $k_{\mathrm{y}} \longrightarrow \infty$ and $R_{M}^{T}=R_{M, \lim }^{T}$.

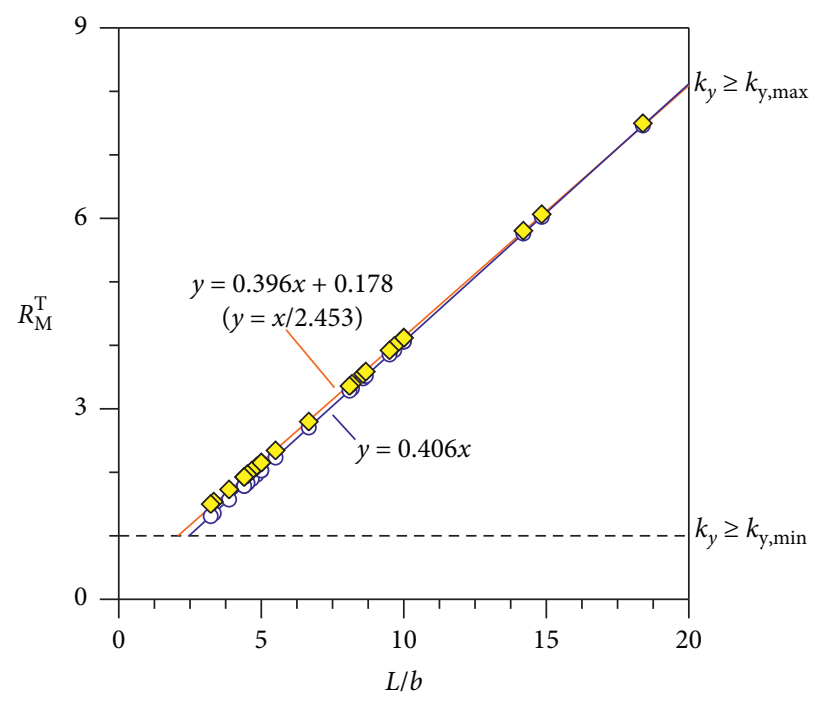

$\diamond \quad R_{\mathrm{M}, \mathrm{lim}}^{\mathrm{T}}$ (analytical)

○ $R_{\mathrm{M}, \text { inf }}^{\mathrm{T}}$ (analytical)

- Empirical $R_{\mathrm{M}, \mathrm{lim}}^{\mathrm{T}}\left(k_{y} \longrightarrow \infty\right)$

- Empirical $R_{\mathrm{M}, \infty}^{\mathrm{T}}\left(k_{y} \longrightarrow \infty\right)$

- - $\left(k_{y} \longrightarrow 0\right)$

FIgURE 7: Analysis of limit $R_{M}^{T}$ conditions for LR monolithic glass members in LTB as a function of $k_{y}$. 
predictions for the top limit, more in detail, are derived from equation (11) or (12).

Regarding all the possible intermediate conditions of technical interest, a concise calculation example is proposed in Figure 8, where the $R_{M}^{T}$ variation for glass fins with continuous flexible restraints are presented as a function of $k_{y}$. Key variations take the form of modifications for span $L$ (the examined range: $1000-5000 \mathrm{~mm}$ ), section height $b$ $(100-400 \mathrm{~mm})$, and fin thickness $t$ (the examined range: $5-50 \mathrm{~mm})$.

While the grouped members are characterized by a univocal limit $R_{M}^{T}$ value that represents the effects of a rigid continuous LR at the tensioned edge, severe modifications for the intermediate $R_{M}^{T}$ values can be observed when $t$ changes.

Based on Figure 8, a concise definition of $R_{M}^{T}$ trends for general LR glass members with variable geometries and stiffness $k_{y}$ cannot be directly expressed. In this regard, Figure 9 shows how the input parameters can affect the overall prediction of critical buckling moment. More precisely, the analytical estimates are shown in Figure 9(a) in terms of percentage of $R_{M, \lim }^{T}$ as a function of $k_{y}$ for a $3000 \times 300 \mathrm{~mm}$ member with variable thickness. A given $\%$ value and thickness $t$ give evidence of the variability in required $k_{\mathrm{y}}$ to achieve a similar LR effect. Similar considerations can be drawn for Figure 9(a). To achieve a certain \% of LR, the minimum required $k_{y}$ increases with the increase of stiffness (based on $t$ ) in the examined $3000 \times 300 \mathrm{~mm}$ member. Furthermore, modification in the span or height of the glass member also affects the overall LTB performance, as shown in Figure 9(c), for a selection of \% values in terms of $R_{M, \text { lim }}^{T}, k_{y}$ values, and geometrical parameters. In other words, equation (8) can be used case by case for single-LTB calculations or applied iteratively so as to describe the limit conditions and explore the effect of input design parameters.

\subsection{Finite Element Numerical Assessment of Analytical} Results. In order to further assess the analytical approach presented in Section 3.2, a set of FE models was developed in Abaqus/Standard. The numerical study included linear bifurcation analyses that were carried out on various geometrical properties of glass members and also various shear stiffness parameters for the LRs. The critical buckling moment of each beam subjected to a constant and negative bending moment $M_{y}$ was predicted numerically by changing $k_{y}$. As a further attempt of validation, the analysis was also focused on the numerically predicted buckling shapes of the same members (i.e., Figure 6) to qualitatively explore the effects of weak or rigid LRs. Finally, the additional advantage of the developed FE models was represented by the parametric analysis of the selected LR glass members under different load (moment) distributions, so as to include additional configurations that are typical of design applications in the study.

To this aim, the reference FE model schematized in Figure 10 was developed in agreement with earlier studies reported in [31,32]. The typical FE assembly consisted of S4R 4-node, quadrilateral, stress/displacement shell elements with reduced integration and large-strain formulation. For the purpose of the parametric analysis, a linear elastic constitutive law was taken into account for glass ( $E=70 \mathrm{GPa}$ and $v=0.23$ ), while the continuous LR at the tensile edge was described in the form of a set of equivalent shear springs. These springs were placed at each edge node (tensioned edge) of the meshed glass members, with the corresponding shear stiffness given by the unit of length value and the mesh edge. This edge size was derived from a regular mesh pattern of quadrilateral shell elements, whose total number was set in a fixed number for each examined span $L$. Loads and boundaries for the simply supported, fork-end restrained beams in LTB were finally introduced in each FE model by means of bending moments $M_{y}$ applied at the barycentric node of the end sections, as well as nodal translational and rotational restraints for the same cross-sectional nodes.

Selected comparative results from the parametric FE study are reported in Figure 11(a) in the form of predicted $R_{\mathrm{M}}{ }^{\mathrm{T}}$ factor for LR glass beams in LTB as a function of $k_{y}$. Worth of interest is the close correlation of ABAQUS numerical predictions and analytical estimates from equation (8) as far as $k_{y}$ modifies.

In the same Figure 11(a), additional numerical dots are presented for members under triangular or parabolic moment distribution.

For LU members in LTB, it is in fact reasonable to estimate the maximum effects derived from distributed $q$ or midspan concentrated $F$ loads by accounting for an equivalent bending moment that is given by

$$
M_{y} \equiv M_{y, \mathrm{eq}}=\frac{M_{y, \max }}{k_{1}},
$$

with

$k_{1}$, a correction factor depending on the distribution of the applied loads

$M_{y, \max }$, the maximum bending moment due to the applied $q$ or $F$ loads, respectively, that is, $M_{y, \max }=$ $q L^{2} / 8$ (with $k_{1}=1.13$ ) or $M_{y, \max }=F L / 4$ (with $k_{1}=1.32$ )

While computationally efficient for design, equation (13) is not valid for LR members due to the presence of partially rigid, continuous lateral restraints which are able to modify the global LTB behaviour. It was shown, for example, in $[31,32]$ that a compressed edge with continuous LR can severely influence the LTB performance of a given glass member under different loading distributions.

The FE parametric study herein summarized for glass members with LR at the tensioned edge further confirmed some important effects due to the imposed moment distribution for a given member. The extended analysis of various geometries and LR stiffnesses, for instance, gave evidence or a rather stable LTB behaviour, with some influencing effects due to moderately stiff LRs in slender members only. Figures 11(b) and 11(c), in this regard, present the numerically derived correction factor $k_{1}$ (from equations (14a) to (14e)) for a multitude of LR glass members 


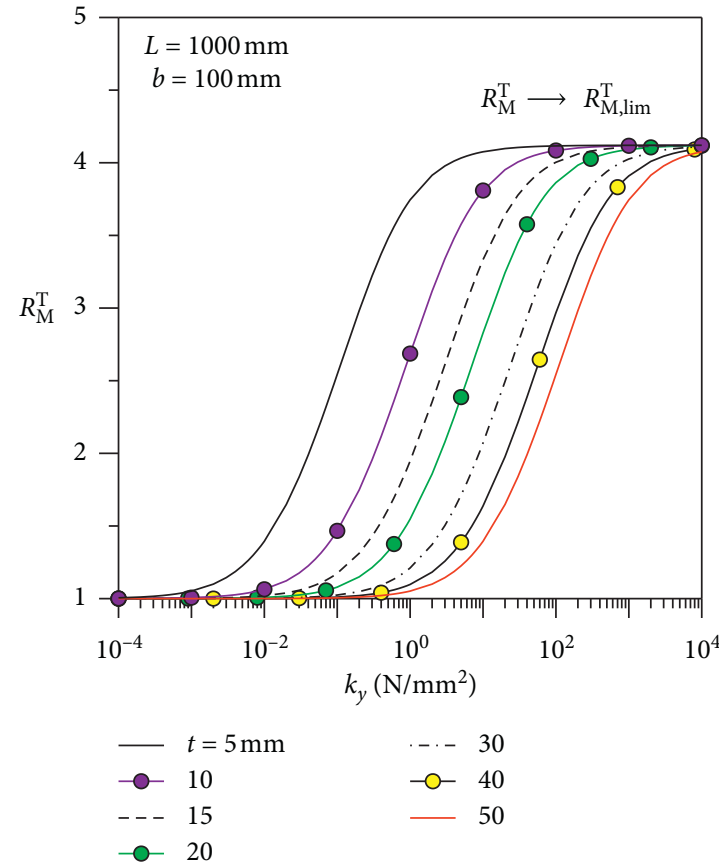

(a)

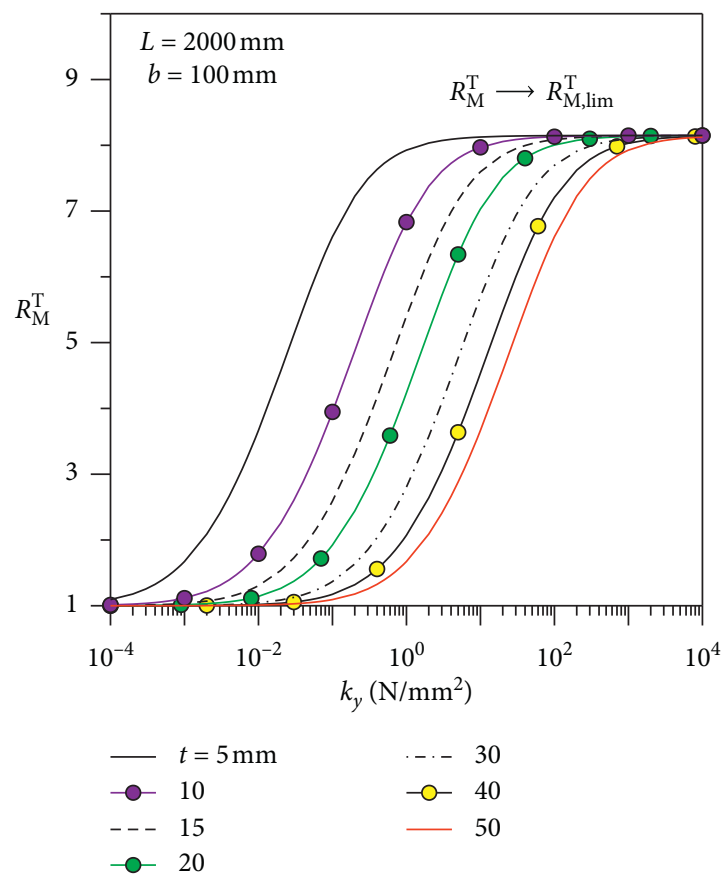

(c)

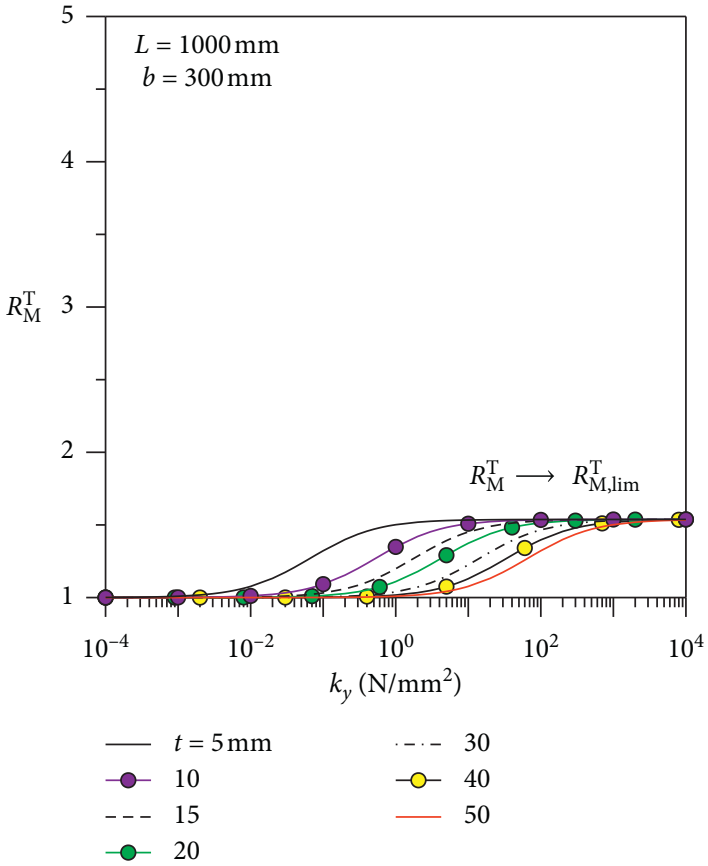

(b)

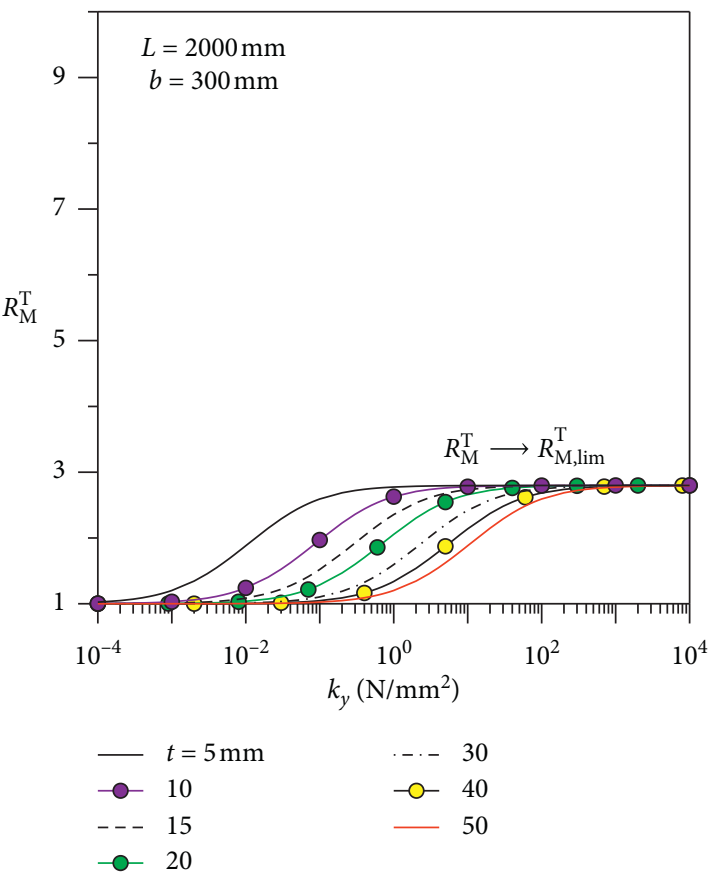

(d)

FIGURE 8: Analysis of critical load variation $\left(R_{M}^{T}\right)$ for selected geometries of monolithic glass beams as a function of the restraint stiffness $k_{y}$ : (a) $L / b=10$, (b) $L / b=3.33$, (c) $L / b=20$, and (d) $L / b=6.66$.

under distributed load $q$ or midspan concentrated load $F$. As shown, the average numerical predictions for $k_{1} \approx 1.13$ and $\approx 1.32$ are still in the order of the conventional values in the simplified model of equation (13). Besides, the same numerical derivations show some deviations as a function of both the input $k_{y}$ and the geometrical parameters. At the first 


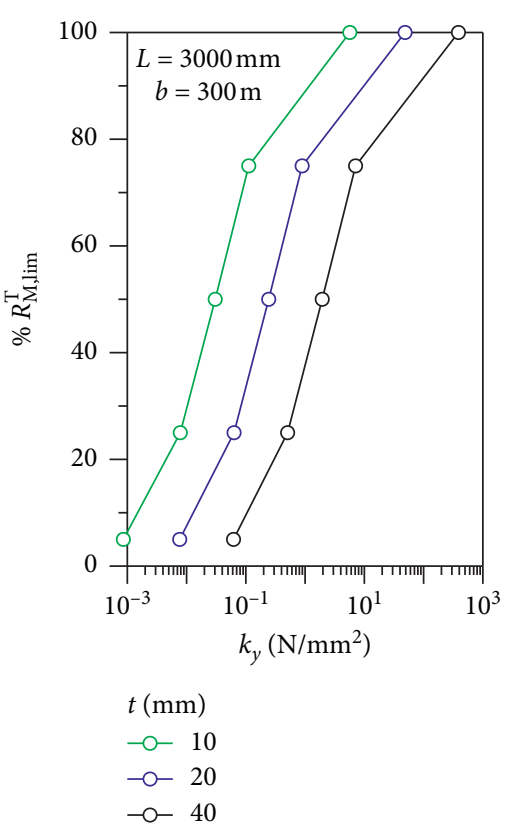

(a)

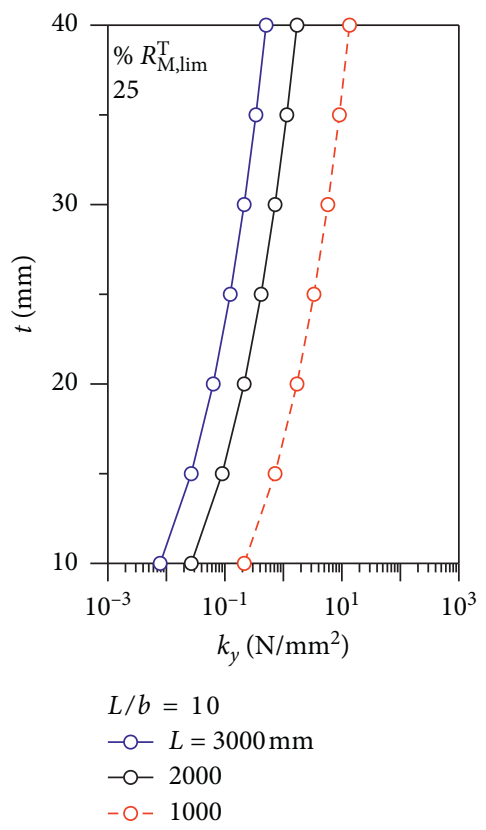

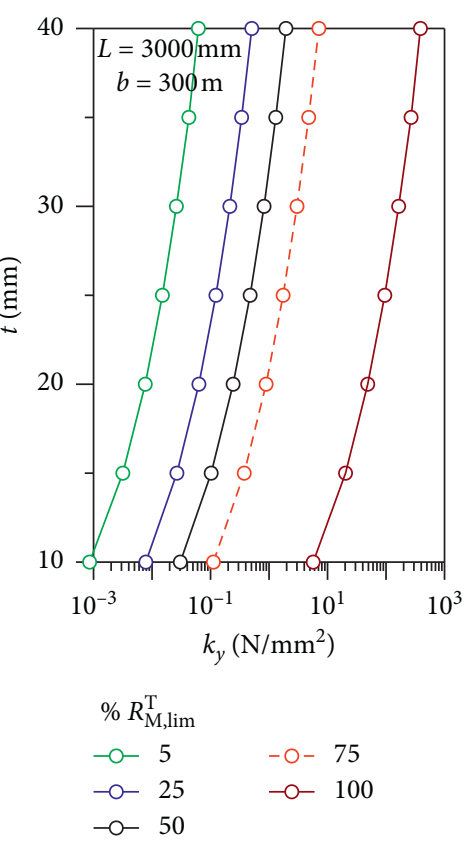

(b)

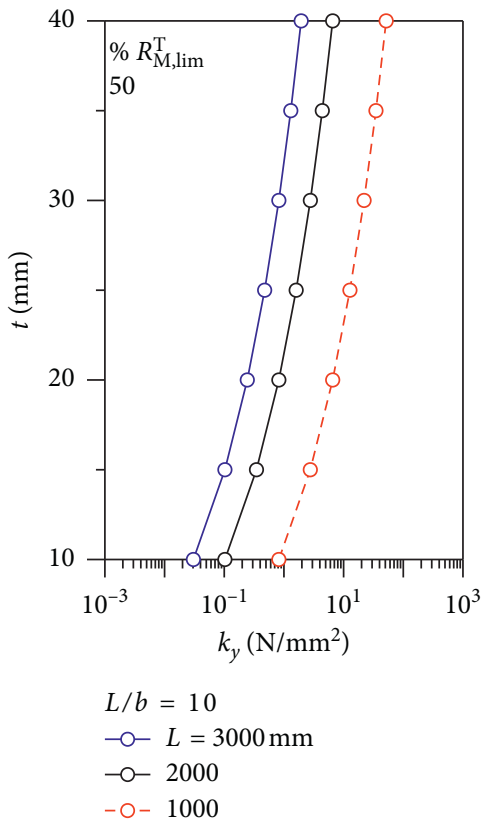

(c)

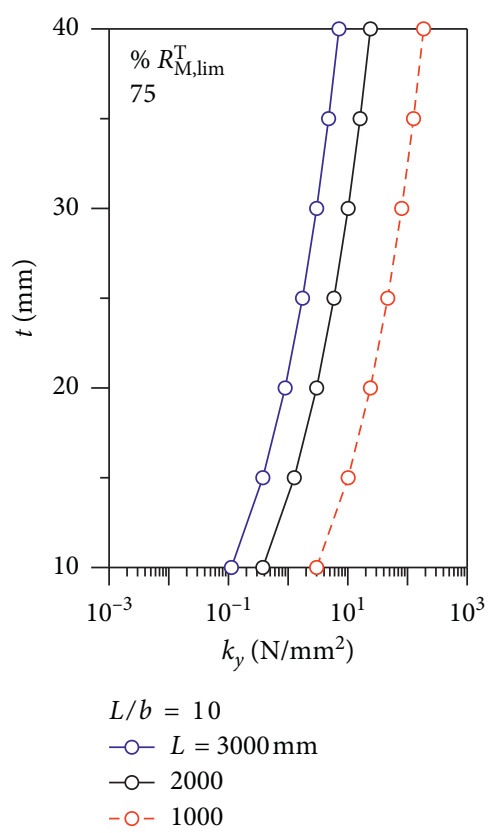

FIgURE 9: Analysis of shear stiffness effects $k_{y}$ on the expected magnification factor $R_{M}^{T}$ for monolithic glass members in LTB.

calculation stage, in this regard, the conventional coefficients $k_{1}$ in equation (13) for the parabolic or triangular moment distributions can be used for preliminary estimates only.

\subsection{Linearized Calculation Procedure}

3.4.1. Magnification Factor $R_{M}^{T}$. From a practical point of view, based on previous results, the overall discussion on the effects of input features for a given LR glass member in LTB manifests in a set of well-defined configurations. It is in fact expected that the possible LR conditions that can be theoretically achieved while changing $k_{y}$, for a general member geometry, are in any case bounded as in equation (9). The comparative analysis as in Figure 8, otherwise, proves that the geometry and thus the flexural/torsional parameters are also influencing parameters for $R_{M}^{T}$.

To develop a practical approach for design, a simplified expression of equation (8) could be, for example, written as

$$
R_{M}^{T}=-A+B \sqrt{C D}
$$

with 


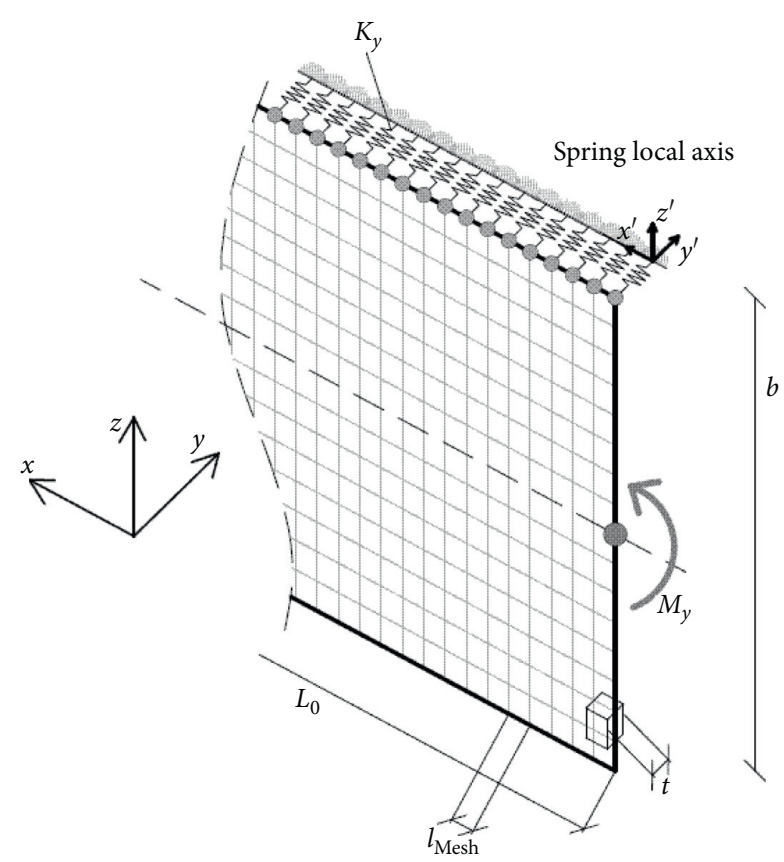

FIgURE 10: Detail of the reference FE numerical model (ABAQUS/ Standard), adapted from $[31,32]$.

$$
\begin{aligned}
& A=\frac{-6 b L^{3} k_{y}}{39.5 b t^{3} E}, \\
& B=\frac{1}{39.5 b t^{3} E}, \\
& C=3 b^{2} L^{2} k_{y}+16 E b t^{3}, \\
& D=12 L^{4} k_{y}+97.4 E b t^{3},
\end{aligned}
$$

but the $A-D$ parameters are still sensitive to a large number of input properties that make the derivation of general empirical expressions of practical use hard.

Alternatively, equation (8) could be simplified and rearranged as

$$
R_{M}^{T}=\frac{-C_{R 1} L^{3}}{t^{3}}+\frac{C_{R 2}}{b t^{3}} \sqrt{b\left(b L^{2}+C_{R 3} t^{3}\right)\left(C_{R 4} L^{4}+b t^{3}\right)},
$$

so as to put in evidence the input $(b, t, L)$ geometrical properties, with $E$, a known parameter for glass. In this case, the advantage of equations (15a)-(15d) is that the values for $C_{R 1}, C_{R 2}, C_{R 3}$, and $C_{R 4}$ are implicitly inclusive of $k_{y}$ features and effects for the LR in use, with

$$
\begin{aligned}
C_{R 1}, C_{R 4} & =f\left(k_{y}\right), \\
C_{R 2} & =f\left(\sqrt{k_{y}}\right), \\
C_{R 3} & =f\left(\frac{1}{k_{y}}\right) .
\end{aligned}
$$

In Figure 12, their general trend is shown with $k_{y}$, and fitting equations are proposed for their calculation. It is possible to see that $C_{R 1}, C_{R 2}$, and $C_{R 4}$ have mostly a null value for a wide range of $k_{y}$ values, and thus, the $R_{M}^{T}$ definition in equation (15a) finds simplification in some terms. On the contrary, $C_{\mathrm{R} 3}$ in Figure 12 has an opposite trend with $k_{y}$ due to the basic assumption of equation (15a). The goal of such a kind of elaboration is that, for a given geometry $(b, t, L)$, the theoretical effectiveness of $k_{y}$ on the actual LTB response can be more easily quantified and addressed, with a graphical approach or with the empirical equations in Figure 12.

The approach is able to fit equation (8) and thus provides accurate estimations for LR members in LTB. Besides, the solution of equations (14a)-(15d) itself still involves the calculation of multiple coefficients to account for their variation with the geometry of glass members and shear stiffness of LRs.

3.4.2. Limit LR Stiffness Values. In order to develop a practical tool, the current study proposes a linearized procedure that is based on the derivation of simple but generalized and reliable empirical formulations. Differing from Section 3.4.1, these equations are useful to directly express the required limit values $k_{y \text {,max }}$ and $k_{y \text {,min }}$ (for a general LR glass member in LTB) that can be associated to the limit conditions of "rigid" or "weak" LR at the tensioned edge.

Let us assume a general glass member in LTB with $(b, t, L)$ geometrical properties and a continuous LR. The proposed procedure first requires the estimation of $k_{y, \max }$ and $k_{y, \min }$ values. Moreover, a linearized trend is then presented for all the intermediate conditions in which $k_{y, \min }<k_{y}<k_{y \text {,max }}$.

(1) Maximum LR Configuration. The LR can be considered as "fully rigid" when its shear stiffness $k_{y}$ is at least equal to a given top limit value $k_{y, \max }$. Given that $k_{y \text {,max }}$ modifies with the geometrical and mechanical features of a given LR member in LTB, this limit condition can be generally detected as

$$
k_{y, \max }:=D_{1} \sqrt{D_{2} k_{y}^{2}+D_{3} k_{y}+D_{4}}-D_{5} k_{y}=0.95 R_{M, \lim }^{T} .
$$

The $D_{1}-D_{5}$ parameters are implicitly inclusive of the member features $(b, t, L)$, given that equation (16) is extrapolated from equations (8) and (12), with the target limit value of $0.95 R_{M \text {,lim }}^{T}$. The advantage of the solution given by equation (16) is the direct expression of the $k_{y}$ value reproducing a mostly complete bracing system for the glass member to analyze. Furthermore, assumed that the thickness $t$ in equation (16) has minimum effects on the top limit value $R_{M \text {,lim }}^{T}$ in the same way as the $L / b$ ratio (as in Figures 7 and 8 and equation (12)), the combination of equations (8), (12), and (16) makes possible to elaborate a further simplification of empirical formulations for the so-defined minimum top threshold $k_{y, \max }$ value. 


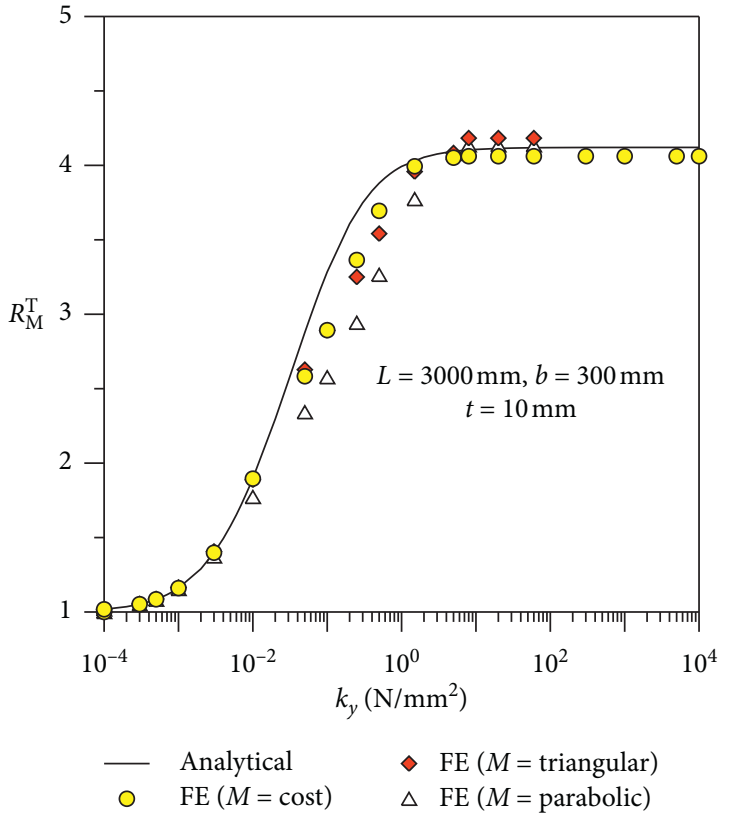

(a)

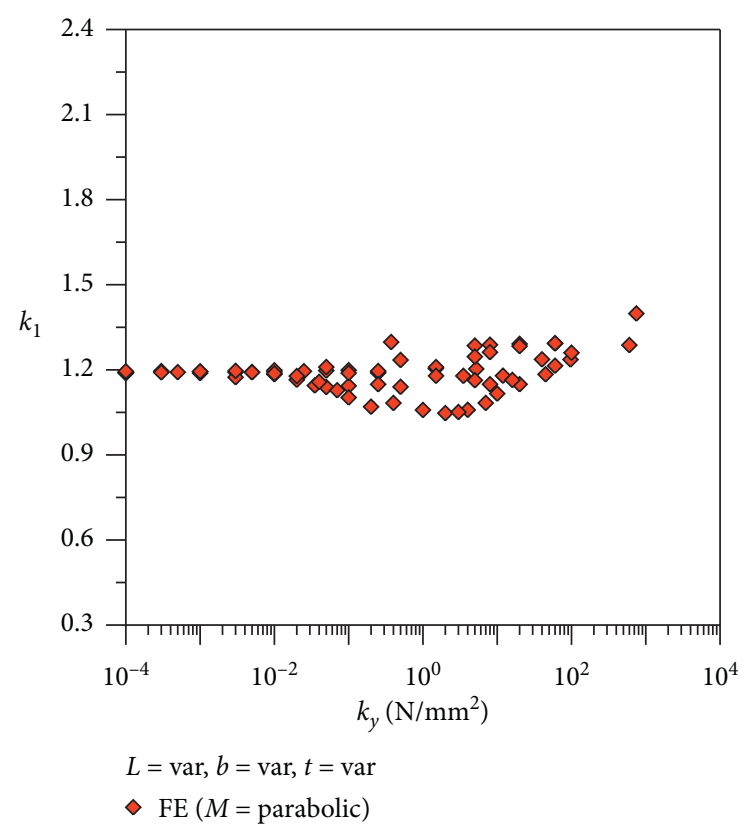

(b)

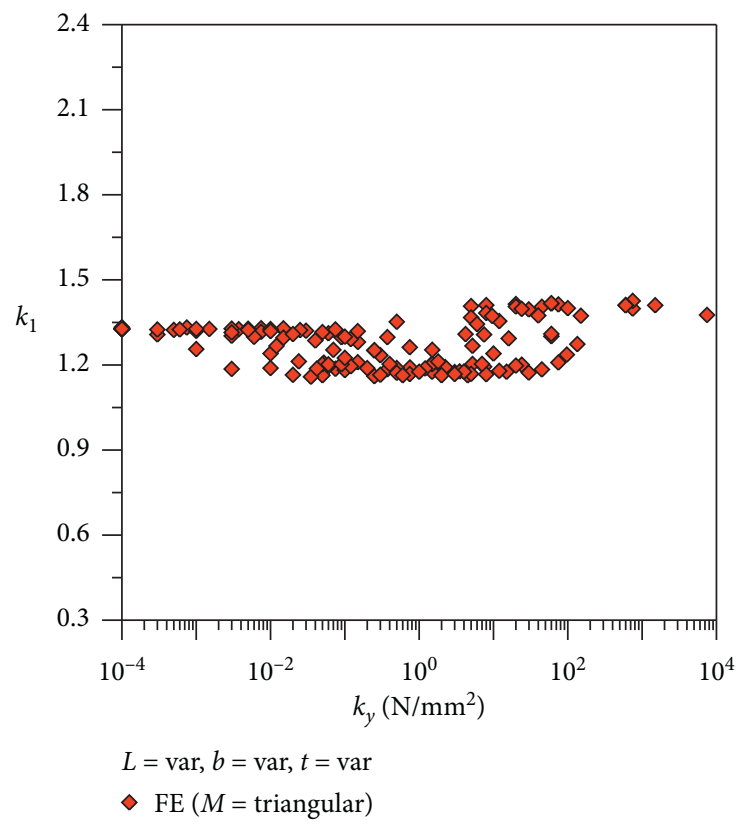

(c)

FIgURE 11: Analytical (equation (9)) and numerical (ABAQUS/Standard) analysis of LR effects on the critical buckling moment of glass beams with the restrained tensioned edge: (a) magnification factor $R_{M}^{T}$ with numerical derivation of the correction factor $k_{1}$ for (b) parabolic or (c) triangular moment distribution.

(2) Minimum LR Configuration. The minimum LTB contribution for a given LR and a general member is a relevant issue in the same way as the "rigid" top condition. In the present study, the LR flexibility is assumed as "efficient" as far as the $k_{y}$ value in use is able to offer at least a minimum increase of LTB resistance for the glass member to verify, compared to its LU configuration. As such, the knowledge of the LU member performance in LTB (that is, $\min \left(R_{M}^{T}\right)=1$ for $k_{y} \longrightarrow 0$ ) is used as a reference to capture a minimum increase of the base theoretical value. The so-defined minimum configuration can be expressed as

$$
k_{y, \min }:=D_{6} \sqrt{D_{2} k_{y}^{2}+D_{3} k_{y}+D_{4}}-D_{7} k_{y}=1.05
$$

where the $D_{2}-D_{7}$ parameters are again defined as in the case of equation (16). Worth of interest is that, in both equations (16) and (17), for a given set of $(b, t, L)$ features, coefficients $D_{2}-D_{4}$ are identical for the $k_{y, \text { max }}$ and $k_{y, \text { min }}$ calculations. From a practical point of view, however, all the $D_{n}$ 


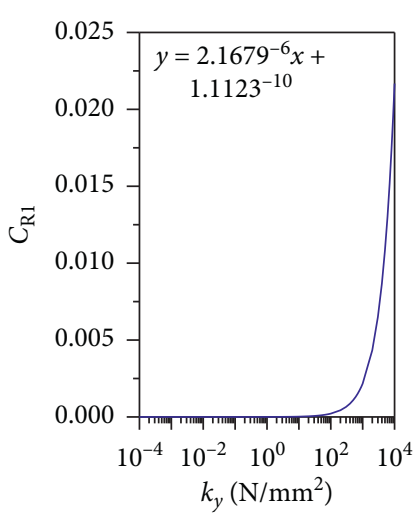

(a)

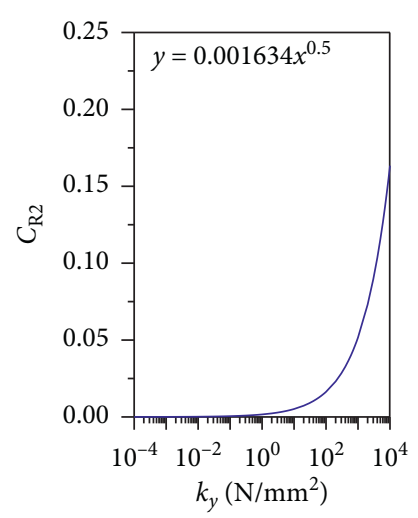

(b)

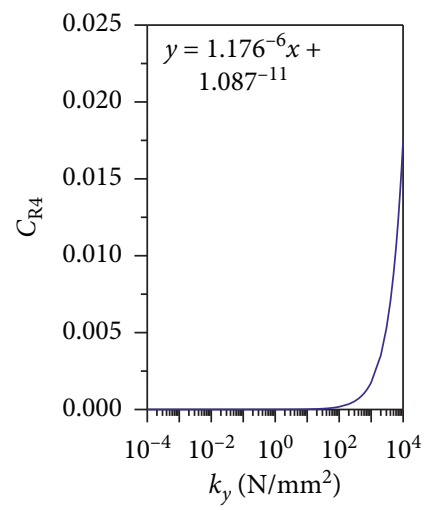

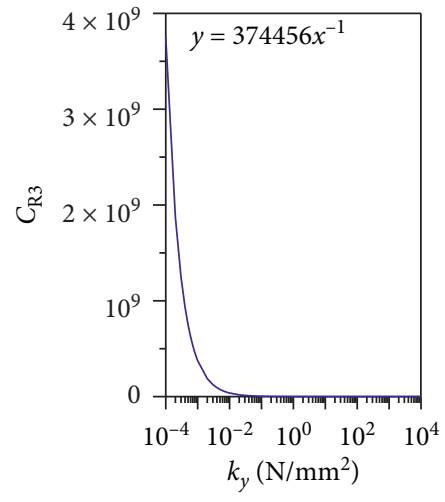

(c)

(d)

FIGURE 12: Derivation of coefficients $C_{R 1}, C_{R 2}, C_{R 3}$, and $C_{R 4}$ for the LTB critical moment analysis of monolithic glass members as a function of the restraint stiffness $k_{\mathrm{y}}$.

coefficients are still characterized by intrinsic complexity that is derived from the mutual effect of all the input properties. Some typical values are reported in Table 3 for a selection of geometries. It is anyway worth of interest that the final result of equations (16) and (17) can support the definition of the generalized expression allowing to account for variations in the member geometry.

(3) Empirical Model for Maximum and Minimum LR Configurations. To facilitate and further simplify the LTB analysis of a general LR member, some typical limit values $k_{y, \max }$ and $k_{y, \text { min }}$ are reported in Figure 13, with practical expressions that are based on geometrical features only. The $k_{y, \text { min }}$ value for a given monolithic member, in particular, is found to follow equation (17) and the trends in Figure 13(a), where it can be seen that

$$
k_{y, \min } \approx\left(\frac{J_{t}}{L} \frac{\gamma_{\min }}{C_{\min }}\right) \cdot \max \left(R_{L / b}, R_{L}\right) .
$$

In equation (18), $J_{t}$ is given by equation (3), $L$ is the span (in $\mathrm{mm}$ ), $\gamma_{\min }=2$ is a calibrated correction factor, and

$$
C_{\text {min }}=1.85 \times 10^{-8}\left(L^{3.7}\right) \text {. }
$$

Moreover, $R_{L / b}$ and $R_{L}$ in equation (18) denote the variation ratio in terms of $(L / b)$ and span $L$, respectively, for the member object of study, compared to the base "reference" conditions that are set, respectively, in $\left(R_{L /}\right.$ $\left.{ }_{b}\right)_{0}=10$ and $\left(R_{L}\right)_{0}=1000 \mathrm{~mm}$.

The same analytical study from equation (16) and summarized in Figures 13(b)-13(d) shows that the top limit value $k_{y, \max }$ corresponding to a "fully rigid" LR at the tensioned edge is given by

$$
k_{y, \max } \approx\left(\frac{J_{t}}{L} \frac{1}{C_{\max }}\right)\left(\frac{1}{\gamma_{\max } \cdot \max \left(R_{L / b}, R_{L}\right)}\right)
$$

with $J_{t}$ from equation (3), $L$ being the span (in $\mathrm{mm}$ ), and

$$
C_{\max }=D_{\max }\left(\frac{L^{-3.5}}{b}\right)
$$

where

$$
D_{\max }= \begin{cases}0.026 L^{2}-59.7 L+45500 & (L \leq 3000 \mathrm{~mm}), \\ 43.2 L-40250 & (L>3000 \mathrm{~mm}),\end{cases}
$$

while $\gamma_{\max }=0.85$ is a calibrated correction factor (for $L \geq 1500 \mathrm{~mm}$ ). In case of short LR members $(L<1500 \mathrm{~mm})$, the second term of equation (20) vanishes.

(4) Intermediate LR Configurations. Once the maximum and minimum LR conditions and parameters are known from equations (18) and (20), the intermediate configurations can be 
TABLe 3: Analytical derivation of limit LR stiffness parameters $k_{y, \min }$ and $k_{y, \max }$ for fully monolithic glass members in LTB.

\begin{tabular}{cccccc}
\hline$L / b$ & $\begin{array}{c}L \\
(\mathrm{~mm})\end{array}$ & $\begin{array}{c}t \\
(\mathrm{~mm})\end{array}$ & $R_{M, \lim }^{T}$ & $\begin{array}{c}k_{y, \min }\left(R_{M}^{T}=1.05\right) \\
\left(\mathrm{N} / \mathrm{mm}^{2}\right)\end{array}$ & $\begin{array}{c}k_{y, \max }\left(R_{M}^{T}=0.95 R_{M, \lim }^{T}\right) \\
\left(\mathrm{N} / \mathrm{mm}^{2}\right)\end{array}$ \\
\hline 10 & 1000 & 10 & 4.138 & $7.699 E-03$ & $1.302 E+01$ \\
10 & 1000 & 20 & 4.138 & $6.159 E-02$ & $1.041 E+02$ \\
10 & 1000 & 30 & 4.138 & $2.079 E-01$ & $3.515 E+02$ \\
10 & 1000 & 40 & 4.138 & $4.927 E-01$ & $8.331 E+02$ \\
10 & 2000 & 10 & 4.138 & $9.624 E-04$ & $1.627 E+00$ \\
10 & 2000 & 20 & 4.138 & $7.699 E-03$ & $1.302 E+01$ \\
10 & 2000 & 30 & 4.138 & $2.598 E-02$ & $4.393 E+01$ \\
10 & 2000 & 40 & 4.138 & $6.159 E-02$ & $1.041 E+02$ \\
10 & 3000 & 10 & 4.138 & $2.852 E-04$ & $4.821 E-01$ \\
10 & 3000 & 20 & 4.138 & $2.281 E-03$ & $3.857 E+00$ \\
10 & 3000 & 30 & 4.138 & $7.699 E-03$ & $1.302 E+01$ \\
10 & 3000 & 40 & 4.138 & $1.825 E-02$ & $3.086 E+01$ \\
\hline
\end{tabular}

roughly estimated as a linear interpolation of the above defined limit values. A practical example is shown in Figure 14 for a $3000 \times 300 \times 10 \mathrm{~mm}$ member with variable $k_{y}$ input.

In conclusion, the developed empirical procedure allows to develop the overall LTB assessment of a given monolithic LR member in LTB based on three simple steps, namely, (i) the prediction of LU critical buckling moment from equation (1a); (ii) the definition of $k_{y}$ limit values from equations (18) and (20); and (iii) the linear interpolation of intermediate $k_{\mathrm{y}}$ conditions as in Figure 14.

\section{Analysis of Laminated Glass Elements}

4.1. Magnification Factor $R_{M}^{T}$. Following Section 3, it is expected that the proposed closed-form formulations could be underconservative for the LTB analysis of LG members in which the bonding foils can provide only partial connection to the glass panels, thus resulting in a minimum shear bonding and torsional stiffness for the layered cross section (Figure 5). This design issue can be efficiently and conservatively addressed as far as the LTB calculation is carried out in the assumption of weak interlayers $\left(G_{\text {int }} \longrightarrow 0\right)$, as in equation (6).

When $z_{M}=-b / 2$ and the elastic LR is applied at the tensioned edge of the LG member to verify, the magnification factor can still be expressed as a function of the $(b, t$, $L$ ) geometrical properties (with $t$ being the thickness of each glass layer) and the shear stiffness $k_{y}$. From equation (6), the rearranged equation (8) for "layered" LG sections with $n_{g}=2$ or 3, respectively, $\left(G_{\text {int }} \longrightarrow 0\right)$ takes the form of

$$
R_{M, 2}^{T}=\frac{-6 b L^{3} k_{y}+\sqrt{\left(6 b^{2} L^{2} k_{y}+64 E b t^{3}\right)\left(6 L^{4} k_{y}+97.4 E b t^{3}\right)}}{79 b t^{3} E}
$$

$$
R_{M, 3}^{T}=\frac{-2 b L^{3} k_{y}-\sqrt{\left(b^{2} L^{2} k_{y}+16 E b t^{3}\right)\left(4 L^{4} k_{y}+97.4 E b t^{3}\right)}}{39.5 b t^{3} E} .
$$

In both $n_{g}=2$ or 3 conditions, from equations (11) and (12), it is also expected that the LR critical buckling moment could ideally reach the top limit value due to the presence of a "rigid" restraint, that is,

$$
M_{\mathrm{cr}, R}^{(E)}=R_{M, \lim }^{T} M_{\mathrm{cr}}^{(E)} \longrightarrow M_{\mathrm{cr}, \infty} \approx \frac{G J_{t, L}}{b},
$$

where the "layered" torsional term $J_{t, L}$ for the composite section is still given by equation (6). The same equation (25) could be theoretically used with $J_{t, M}$ in place of $J_{t, L}$ from equation (6). The achievement of monolithic torsional bonding, however, is a difficult condition to realize in practical LG solutions, as also previously noted.

For a general LG section, disregarding the shear rigidity $G_{\text {int }}$, the magnification factor $R_{M}^{T}$, due to a variable LR flexibility $k_{y}$, can, at maximum, achieve the top limit value $R_{M, \lim }^{T}$ that is quantified in

$$
R_{M, \lim }^{T}=\left\{\begin{array}{l}
R_{M, 2, \lim }^{T} \approx \frac{L}{1.7957 b} \\
R_{M, 3, \lim }^{T} \approx \frac{L}{2.035 b},
\end{array}\right.
$$

with $n_{g}=2$ or 3 , respectively. The assumption of a "layered" configuration is on the conservative side and can represent a minimum value that the LG member object of study will be able to offer in LTB conditions with flexible LRs.

Figure 15, in this regard, shows the correlation of the limit $R_{M}^{T}$ values defined above. It is worth of interest that $n_{g}$ directly reflects in a possible limitation of the LTB performance capacity for the member to verify. In any case, the overall LTB performance with a rigid LR $\left(k_{y} \geq k_{y \text {,max }}\right)$ is not able to equal the maximum performance of a fully monolithic glass member, and this is a major effect of composite "layered" properties. The use of monolithic equivalent thickness formulations as in Tables 1 and 2, with the empirical equations presented for fully monolithic LR glass members in LTB, can represent an alternative solution as far as the intrinsic effects on composite flexural and torsional stiffnesses are properly considered.

From the interpolation and iterative calculation of equations (23) and (24), finally, limit values $k_{y}$ for LG sections are reported in Tables 4 and 5. 

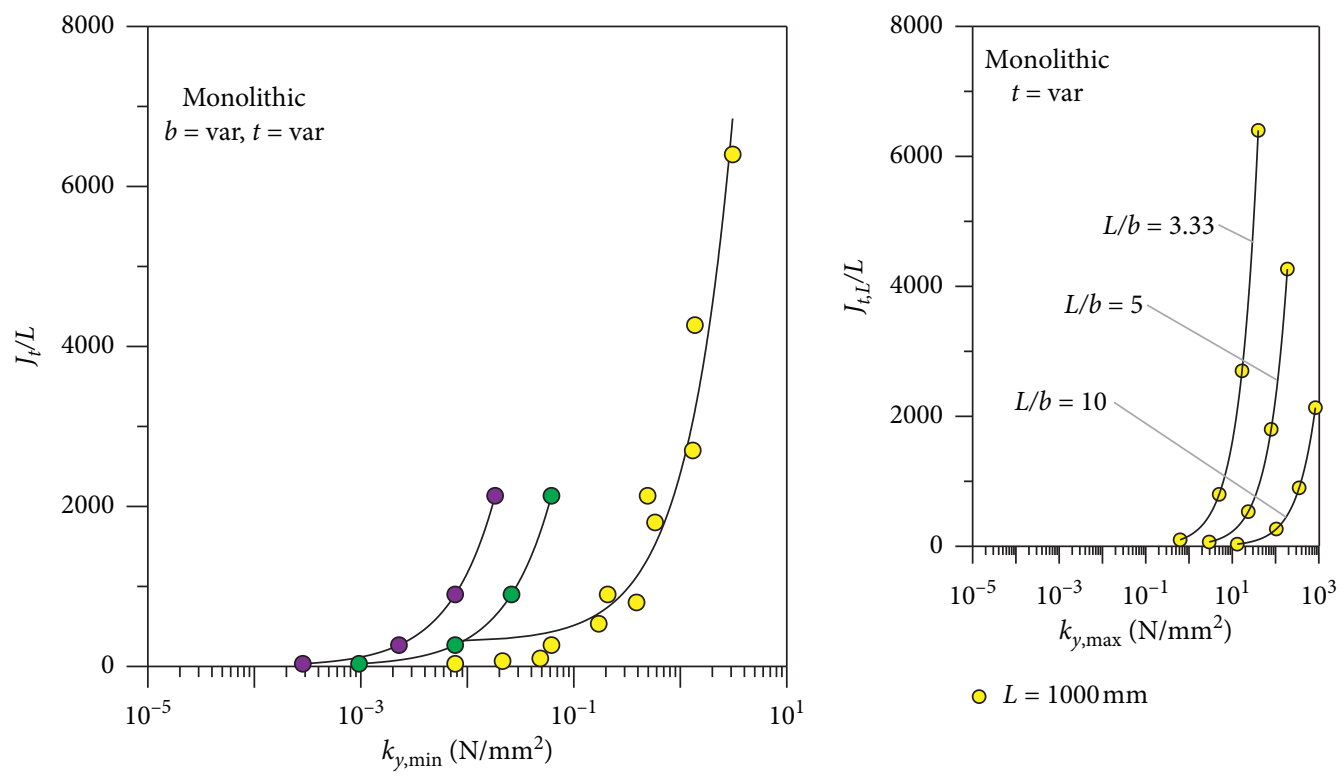

○ $L=1000 \mathrm{~mm}$

- $L=3000 \mathrm{~mm}$

- 2000

○ 1000

(a)

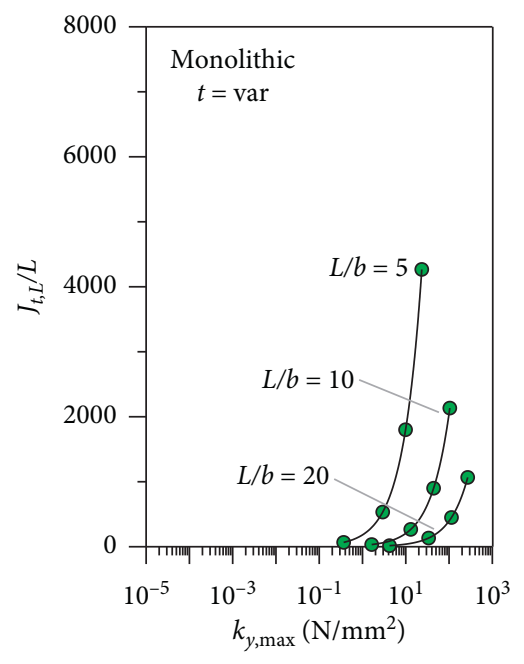

○ $L=2000 \mathrm{~mm}$

(b)

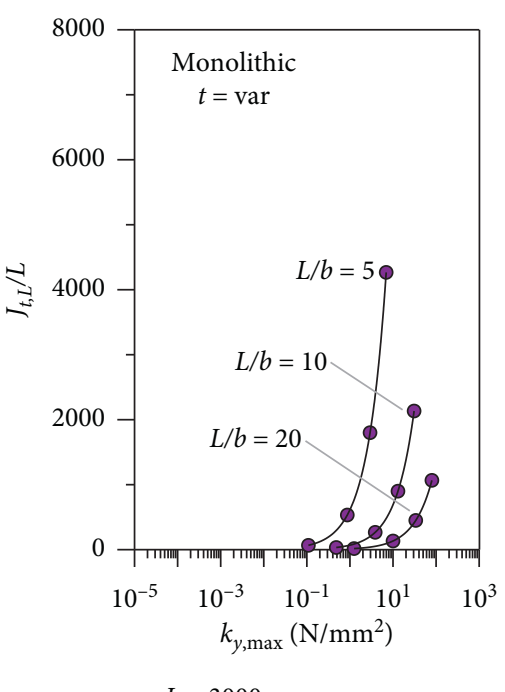

(c)

(d)

FIGURE 13: Analytical derivation of limit LR parameters (a) $k_{y, \min }$ and (b)-(d) $k_{y \text {,max }}$ for monolithic glass members in LTB.

4.1.1. Layered Members with $n_{g}=2\left(G_{i n t}=0\right)$. The extended analysis of parametric analytical data further allows to highlight that the $k_{y \text {,min }}$ value has a typical trend as in Figure 16 and can be estimated as

$$
k_{y, \min } \approx \frac{J_{t, L}}{L} \frac{1}{C_{2, \min }},
$$

with

$$
C_{2, \min }=\max (1 ; 96.7 L-105473)
$$

Furthermore, the upper limit value $k_{y, \max }$ can be roughly derived as

$$
k_{y, \max } \approx \frac{J_{t, L}}{L} \frac{1}{C_{2, \max }},
$$

with

$$
C_{2, \max }=D_{2, \max } e^{-0.2(L / b)}
$$$$
D_{2, \max }=\max \left(1 ; 0.45 \frac{L}{b}-315\right) \text {. }
$$ 


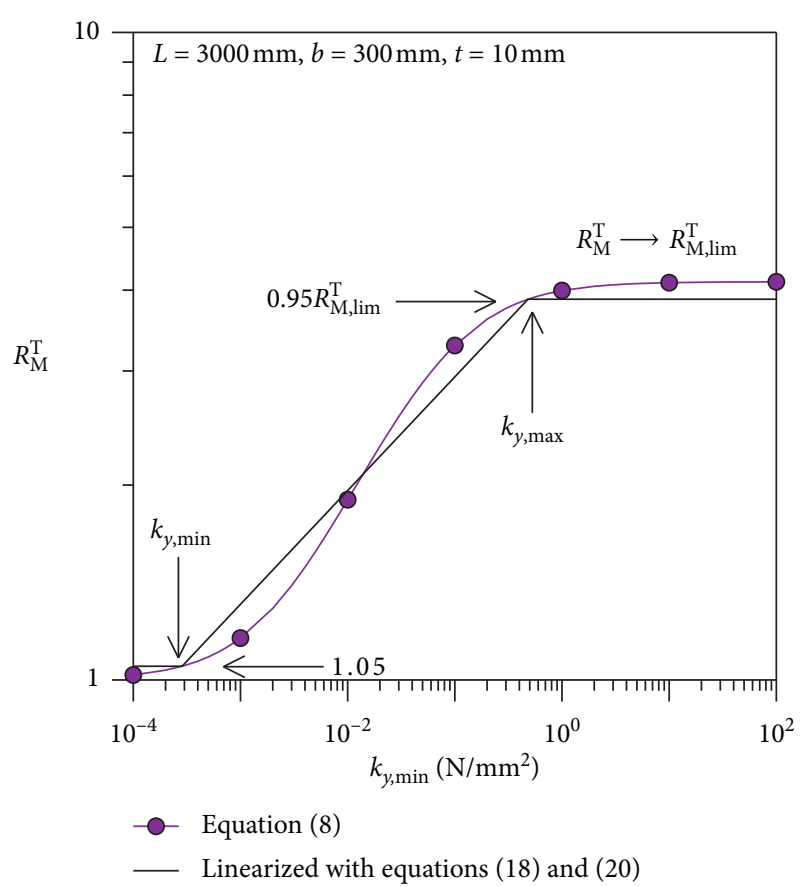

Figure 14: Analysis of critical load variation (magnification factor $R_{M}^{T}$ ) for monolithic glass beams, as a function of $k_{y}$, based on equation (8) or the simplified linearized procedure (from equations (18) and (20)).

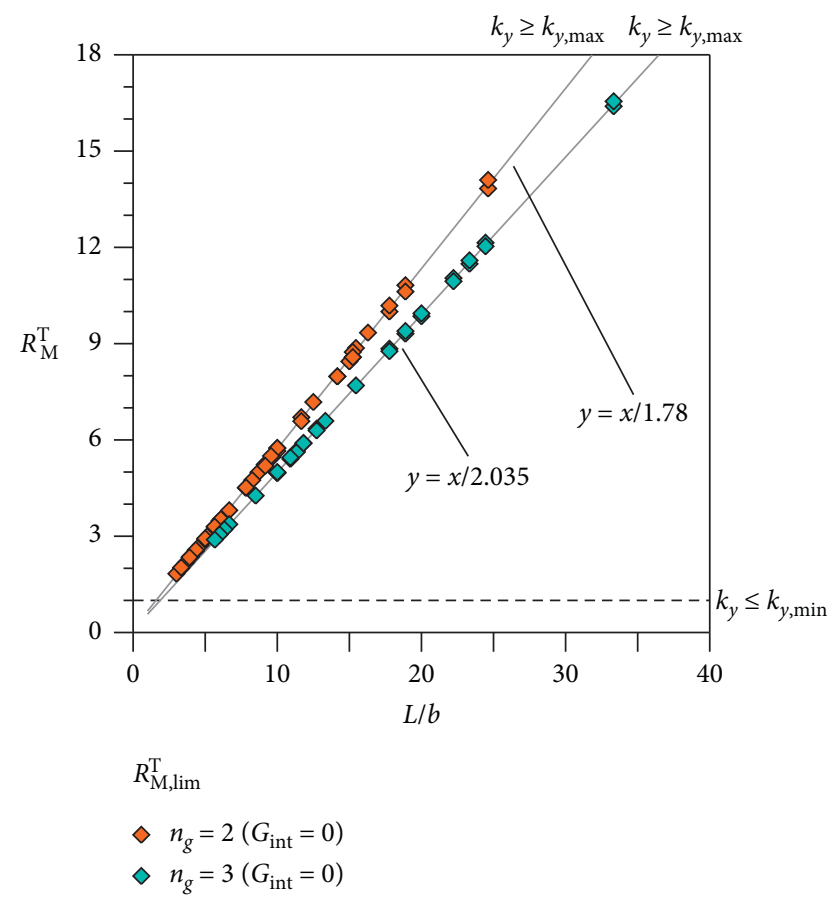

FIGURE 15: Analysis of limit $R_{M}^{T}$ conditions for "layered" LG members in $\operatorname{LTB}\left(G_{\text {int }}=0\right)$ as a function of $k_{y}$.

4.1.2. Layered Members with $n_{g}=3 \quad\left(G_{i n t}=0\right)$. The limit stiffness values for LRs are found to follow the trends in Figure 17. The analysis of collected analytical data further allows to express the limit values as

$$
k_{y, \min } \approx \frac{J_{t, L}}{L} \frac{1}{C_{3, \min }},
$$

where

$$
\begin{aligned}
& C_{3, \min } \approx 1.45 C_{2, \min }, \\
& k_{y, \text { max }} \approx \frac{J_{t, L}}{L} \frac{1}{C_{3, \max }},
\end{aligned}
$$

with

$$
\begin{aligned}
& C_{3, \max }=D_{3, \max } e^{-0.34(L / b)}, \\
& D_{3, \max }=\max \left(1 ; 1.45 \frac{L}{b}-1352\right) .
\end{aligned}
$$

\section{LTB Example for a Laminated Glass Fin $\left(n_{g}=2\right)$}

In conclusion, a calculation example is presented to address the LTB stability check of LG members that are used to brace a glass wall against wind suction based on the simplified approach herein developed. The case study system takes inspiration and input data from [4].

5.1. Geometry and Loads. The wall has dimensions $H=4 \mathrm{~m} \times B=8 \mathrm{~m}$ and is sustained (for dead loads only) by another supporting system (Figure 18). This means that each fin comes into play with the action of wind. Each $H=L=4 \mathrm{~m}$ long $\times b=0.45 \mathrm{~m}$ fin is $i=2 \mathrm{~m}$ spaced and connected to the wall panels by means of a continuous silicone joint, able to provide a certain structural interaction between them. The cross section of each fin consists of LG obtained from heat-strengthened glass and a middle PVB layer $\left(n_{g}=2\right)$. The nominal thickness of each glass layer is set in $t=t_{1}=t_{2}=15 \mathrm{~mm}$, with $t_{\text {int }}=1.52 \mathrm{~mm}$ for PVB foils.

The gust of wind (peak speed averaged over 3 seconds) has a pressure equal to $p_{\text {wind }}=1.2 \mathrm{kN} / \mathrm{m}^{2}$ that corresponds to a $q=p_{\text {wind }} \times i=2.4 \mathrm{kN} / \mathrm{m}$ distributed load on each fin. For LTB purposes, moreover, the self-weight of the glass fin is disregarded. A conventional load time duration of 3 seconds and a reference temperature $T=30^{\circ} \mathrm{C}$ are considered for the design action. In addition, the strengthening and stiffening contribution of LRs is conservatively neglected, and LU fins in LTB are preliminary verified.

The maximum bending moment at the midspan section of each fin is

$$
M_{\max }^{q}=\frac{\gamma_{q} q L^{2}}{8}=7.2 \mathrm{kNm},
$$

with $\gamma_{q}=1.5$, the partial safety factor for live loads.

5.2. Design Buckling Strength. The design tensile strength $f_{g ; d}$ and the characteristic strength for buckling $f_{g ; k ; s t}$ are two mandatory parameters that must be first calculated for glass. The first one is given by 
TABLE 4: Analytical derivation of limit LR values $k_{y, \min }$ and $k_{y, \max }$ for LG members in LTB $\left(n_{g}=2\right.$ and $\left.G_{\text {int }}=0\right)$.

\begin{tabular}{lcccc}
\hline$L / b$ & $L(\mathrm{~mm})$ & $t(\mathrm{~mm})$ & $k_{y, \min }\left(R_{M}^{T}=1.05\right)\left(\mathrm{N} / \mathrm{mm}^{2}\right)$ & $\left.k_{\mathrm{y}, \max }\left(R_{M}^{T}=0.95 R_{M, \mathrm{lim}}^{T}\right)(\mathrm{N} / \mathrm{mm})^{2}\right)$ \\
\hline 10 & 1000 & 8 & $3.797 E-03$ & $1.263 E+01$ \\
10 & 1000 & 10 & $7.288 E-03$ & $2.179 E+01$ \\
10 & 1000 & 12 & $1.245 E-02$ & $3.534 E+01$ \\
10 & 1000 & 8 & $2.416 E-02$ & $6.550 E+01$ \\
10 & 2000 & 10 & $4.706 E-04$ & $1.581 E+00$ \\
10 & 2000 & 12 & $9.109 E-04$ & $2.724 E+00$ \\
10 & 2000 & 15 & $1.556 E-03$ & $4.417 E+00$ \\
10 & 2000 & 8 & $3.019 E-03$ & $8.187 E+00$ \\
10 & 3000 & 10 & $1.401 E-04$ & $4.689 E-01$ \\
10 & 3000 & 12 & $2.699 E-04$ & $8.070 E-01$ \\
10 & 3000 & 15 & $4.611 E-04$ & $1.309 E+00$ \\
10 & 3000 & & $8.946 E-04$ & $2.426 E+00$ \\
\hline
\end{tabular}

TABLE 5: Analytical derivation of limit LR values $k_{y, \min }$ and $k_{y, \max }$ for LG members in LTB $\left(n_{g}=3\right.$ and $\left.G_{\text {int }}=0\right)$.

\begin{tabular}{lcccc}
\hline$L / b$ & $L(\mathrm{~mm})$ & $t(\mathrm{~mm})$ & $k_{y, \min }\left(R_{M}^{T}=1.05\right)\left(\mathrm{N} / \mathrm{mm}^{2}\right)$ & $k_{\mathrm{y}, \max }\left(R_{M}^{T}=0.95 R_{M, l i m}^{T}\right)\left(\mathrm{N} / \mathrm{mm}^{2}\right)$ \\
\hline 10 & 1000 & 8 & $7.586 E-03$ & $1.564 E+01$ \\
10 & 1000 & 10 & $1.480 E-02$ & $2.882 E+01$ \\
10 & 1000 & 12 & $2.532 E-02$ & $4.840 E+01$ \\
10 & 15 & $4.950 E-02$ & $9.209 E+01$ \\
10 & 2000 & 8 & $9.448 E-04$ & $1.958 E+00$ \\
10 & 2000 & 10 & $1.850 E-03$ & $3.602 E+00$ \\
10 & 2000 & 12 & $3.164 E-03$ & $6.050 E+00$ \\
10 & 2000 & 15 & $6.188 E-03$ & $1.151 E+01$ \\
10 & 3000 & 10 & $2.807 E-04$ & $5.793 E-01$ \\
10 & 3000 & 12 & $5.483 E-04$ & $1.069 E+00$ \\
10 & 3000 & 15 & $9.376 E-04$ & $1.792 E+00$ \\
10 & 3000 & & $1.833 E-03$ & $3.411 E+00$ \\
\hline
\end{tabular}

$$
f_{g ; d}=\frac{k_{\bmod } k_{e d} k_{s f} \lambda_{g A} \lambda_{g A} f_{g ; k}}{R_{M} \gamma_{M}}+\frac{k_{e}{ }_{d}^{\prime} k_{v}\left(f_{b ; k}-f_{g ; k}\right)}{R_{M ; v} \gamma_{M ; v}}=24.49 \mathrm{MPa},
$$

with all the input coefficients derived from [4], while

$$
f_{g ; d}=k_{\bmod } k_{e d} k_{s f} \lambda_{g A} \lambda_{g A} f_{g ; k}+k_{e d}{ }_{d}^{\prime} k_{v}\left(f_{b ; k}-f_{g ; k}\right)=44.19 \mathrm{MPa} \text {. }
$$

The shear stiffness value $G_{\text {int }}^{q}=0.8 \mathrm{MPa}$ should also be taken into account in PVB for the estimation of the design buckling strength of each fin $\left(3 \mathrm{~s}, T=30^{\circ} \mathrm{C}\right)$. For safety issues, it is assumed that $T=50^{\circ} \mathrm{C}$, and thus, $G_{\text {int }}^{q}=0.44 \mathrm{MPa}$. The equivalent glass thickness for each fin is first calculated from Tables 1 and 2, where

$$
\begin{aligned}
t_{\mathrm{eq}} & =18.56 \mathrm{~mm}, \\
J_{z, \text { eq }} & =4.252 \times 10^{5} \mathrm{~mm}^{4}, \\
J_{t, \text { tot }} & =J_{t, 1}+J_{t, 2}+J_{t, \text { int }}=1.095 \times 10^{6} \mathrm{~mm}^{4},
\end{aligned}
$$

where it is possible to notice the limited torsional contribution of the interlayer ("layered" limit condition for torsion).

Disregarding the presence of continuous LR at the tensioned edge, the normalized torsional slenderness ratio of each fin is preliminary calculated:

$$
\bar{\lambda}_{\mathrm{LT}}^{\mathrm{q}}=\sqrt{\frac{W_{x} f_{g ; k ; \mathrm{st}}}{M_{\mathrm{cr}}^{(E)}}}=1.114,
$$

with

$$
M_{\mathrm{cr}}^{(E)}=k_{1} \frac{\pi}{L} \sqrt{E J_{z, \mathrm{eq}} G J_{t, \mathrm{tot}}}=2.702 \cdot 10^{7} \mathrm{Nmm},
$$

Euler's critical buckling moment of the reference LU fin.

The torsional buckling reduction factor for the LU fin would give

$$
\chi_{\mathrm{LT}}=\frac{1}{\Phi+\sqrt{\Phi^{2}-\bar{\lambda}_{\mathrm{LT}}^{2}}}=0.561
$$

where

$$
\Phi=0.5\left[1+\alpha_{\mathrm{imp}}\left(\bar{\lambda}_{\mathrm{LT}}-\alpha_{0}\right)+\bar{\lambda}_{\mathrm{LT}}^{2}\right]=1.239, \quad\left(\alpha_{\mathrm{imp}}=0.26, \alpha_{0}=0.2\right),
$$

and thus,

$$
M_{b, R d}^{q}=\chi_{\mathrm{LT}} M_{R}=\chi_{\mathrm{LT}} W_{x} f_{g ; d}=1.042 \cdot 10^{7} \mathrm{Nmm} .
$$

The LTB verification of the examined fins (LU preliminary hypothesis) under wind suction is positively satisfied, given that 


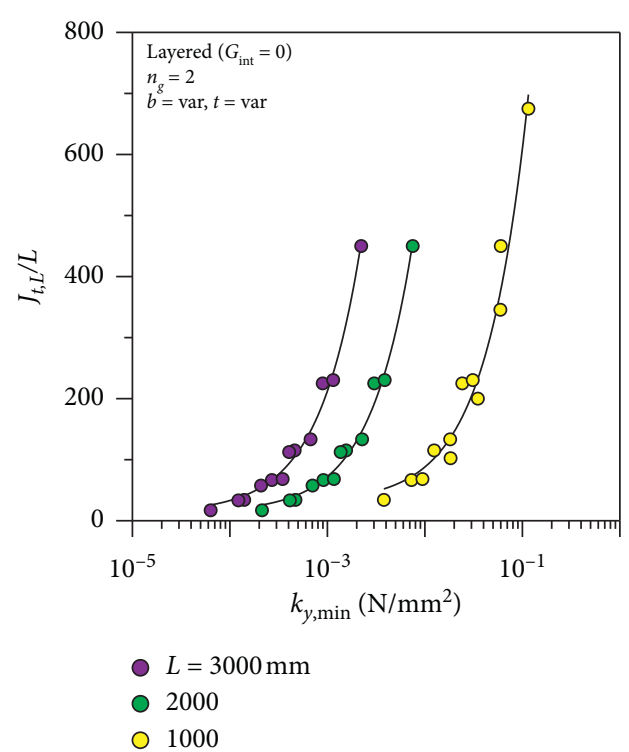

(a)

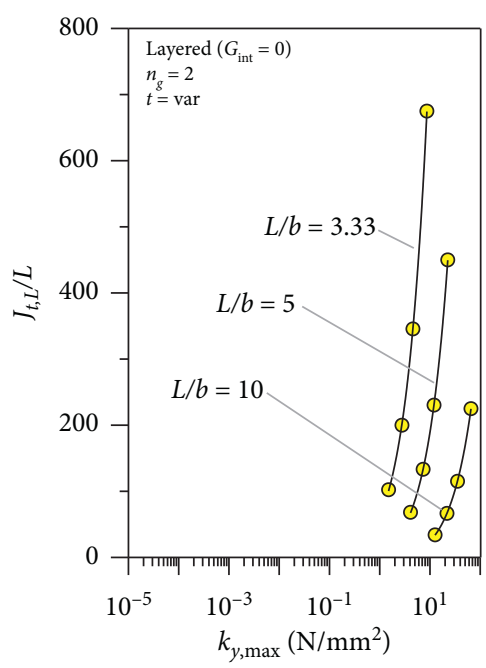

○ $L=1000 \mathrm{~mm}$

(b)

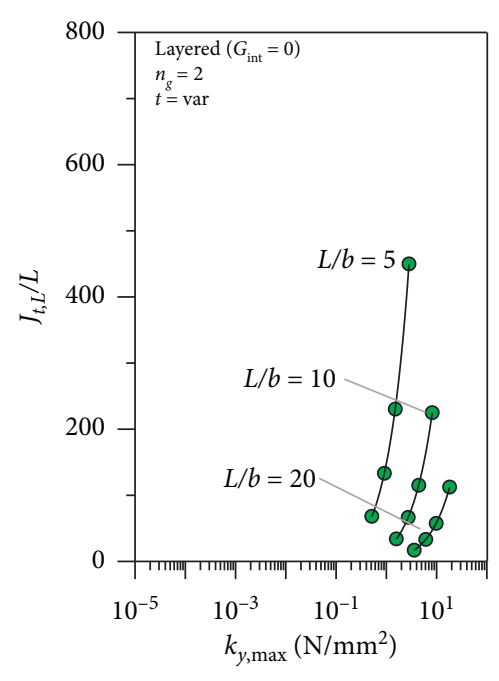

- $L=2000 \mathrm{~mm}$

(c)

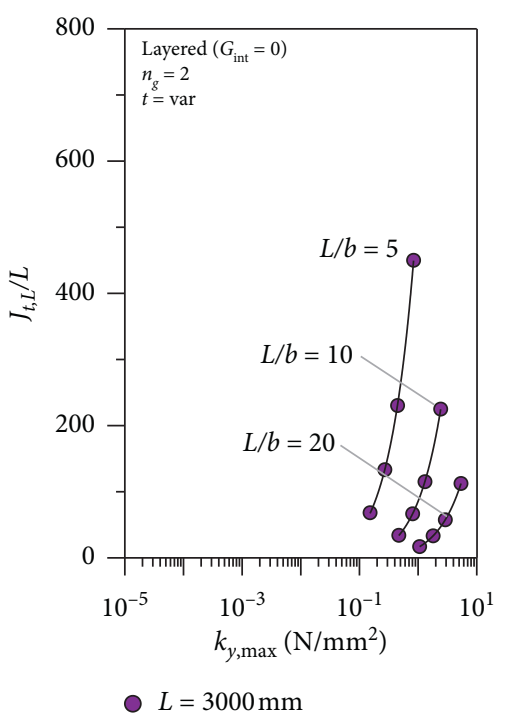

(d)

FIGURE 16: Analytical derivation of limit LR parameters (a) $k_{y, \min }$ and (b)-(d) $k_{y, \max }$ for laminated glass members in LTB $\left(n_{g}=2\right.$, layered limit).

$$
\frac{M_{E d}^{q}}{M_{b, R d}^{q}}=\frac{7.20}{10.42}=0.69 \leq 1 .
$$

However, it is worth to note that the LR fins can take advantage of the beneficial contribution of the continuous joint at the tensioned edge, as discussed in Section 4 for LG members. Disregarding the exact $k_{y}$ values, the top "layered" condition is associated to

$$
R_{M, 2, \lim }^{T} \approx \frac{L}{1.7957 b}=4.95 \text {. }
$$

The knowledge of allowable theoretical performances for the examined fin geometry can thus be used for the LTB verification check of the LR members and for the detailed design of the joint.

The iterative LTB design check, based on $k_{y, \min } \leq k_{y} \leq k_{y, \max }$ and the developed linearization approach, has, in fact, a direct effect on $R_{M}^{T}$, thus on the corresponding $M_{R, \mathrm{cr}}^{(E)}$ and the LTB buckling parameters $\bar{\lambda}_{\mathrm{LT}}$ and $\chi_{\mathrm{LT}}$ that govern the above LTB verification condition. From $R_{M_{-} 2 \text {,lim, }}^{T}$, the top condition gives $\chi_{\mathrm{LT}}=0.908$ and 


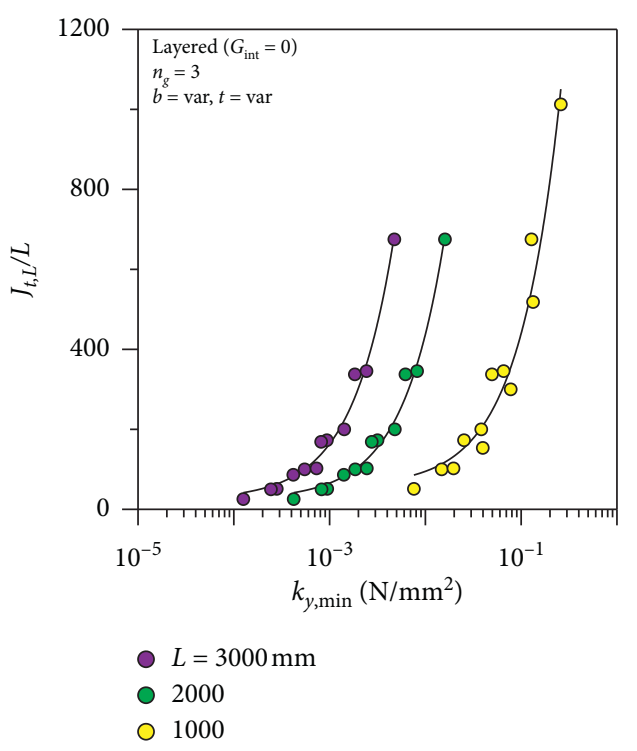

(a)

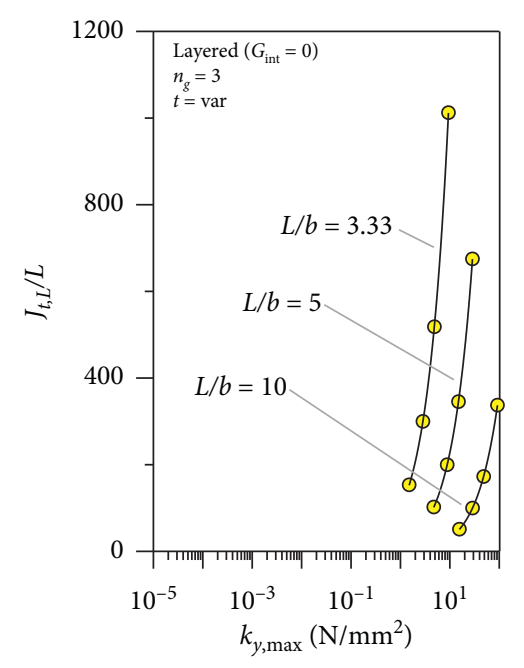

○ $L=1000 \mathrm{~mm}$

(b)

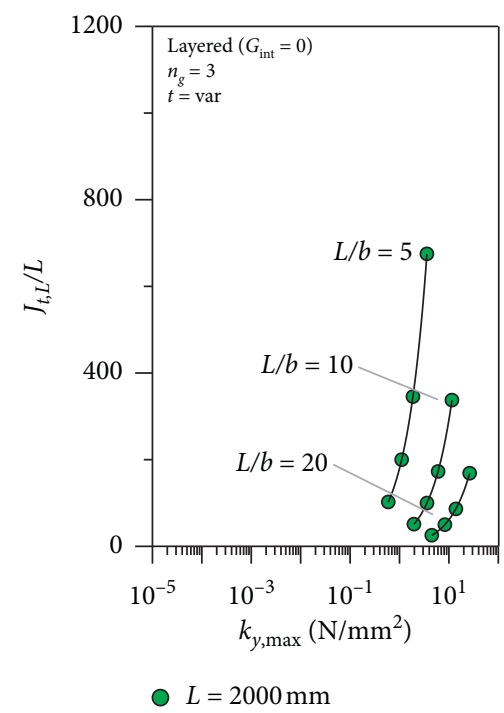

(c)

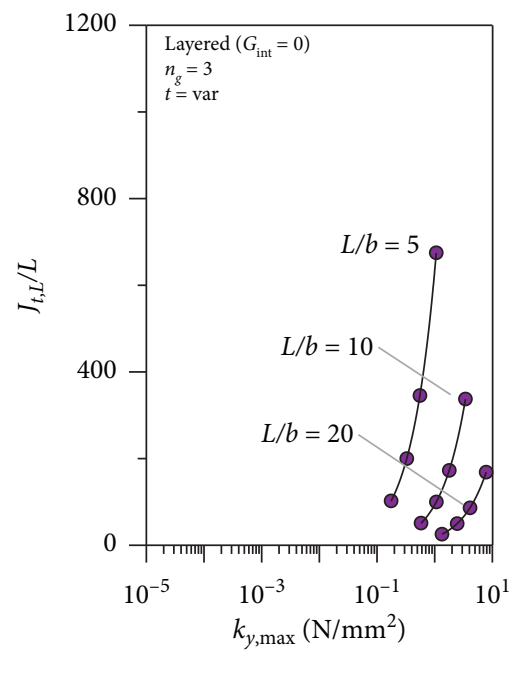

- $L=3000 \mathrm{~mm}$

(d)

FIGURE 17: Analytical derivation of limit LR parameters (a) $k_{y, \min }$ and (b)-(d) $k_{y, \max }$ for laminated glass members in LTB $\left(n_{g}=3\right.$, layered limit).

$$
\frac{M_{E d}^{q}}{M_{b, R d}^{q}}=0.43 \leq 1 .
$$

At the same time, it is possible to notice that the calculated $k_{y \text { min }}$ value is rather small. Considering some typical bonds and LR joint sections in use for similar applications (see, for example, [30-32]), this suggests that even a minor LR joint can offer a certain beneficial contribution in terms of stiffness and resistance for the investigated geometry and thus enforce the proposed analytical procedure for LR members in LTB. Besides, it has to be noted that the current approach does not exclude the need of separate design checks that the same fins should satisfy in terms of ultimate resistance and serviceability deformation under the imposed design loads. 


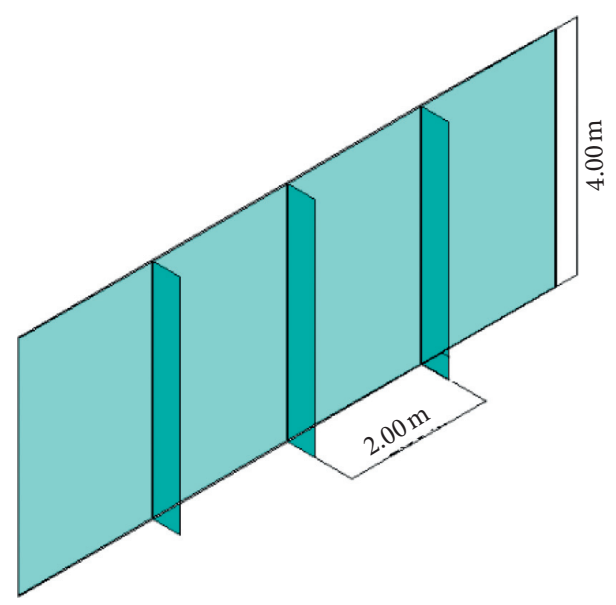

FIgURE 18: Reference geometry for the LG fins in LTB.

\section{Conclusions}

This paper investigated the lateral torsional buckling (LTB) analysis of glass members with continuous flexible lateral restraint (LR) at the tensioned edge. The condition is typical of fins and stiffeners that are used to brace roofs and facade panels under negative pressure.

To provide empirical formulations of practical use in support of design, analytical models validated toward finite element numerical simulation have been discussed, giving evidence of the effects of geometrical and mechanical input parameters on the overall performance of LR glass members in LTB. As shown, major challenges are represented by the presence of multiple input parameters that mutually affect the final LTB performance for a given member. This suggests the need of computationally practical but reliable tools that could account for the main parameters of design.

Empirical formulations have thus been presented for glass members with tensioned edge in LR and characterized by a fully monolithic or laminated (with $n_{g}=2$ or 3 glass layers) resisting section. Practical expressions have been proposed to estimate the threshold shear stiffness parameters of continuous LRs in use for a given member geometry, so as to facilitate the critical buckling moment calculation. The major advantage is taken from a linearization procedure that interpolates the effects of variable LR stiffnesses for a general member geometry, starting from the top and bottom limit conditions of rigid or weak restraints. The reported study also showed that, for members under different moment distributions (such as parabolic or triangular), the presence of LRs can still be efficiently accounted in the form of traditional correction factors for the critical buckling load predictions, thus facilitating the overall LTB design process.

\section{Data Availability}

The data used to support the findings of this study are available upon request to the author.

\section{Conflicts of Interest}

The author declares that there are no conflicts of interest.

\section{References}

[1] CEN/TC 250, prCEN/TS xxxx-1: 2019-in-plane loaded glass components, CEN-European Committee for Standardization, Brussels, Belgium, 2019.

[2] CEN/TC 250, prCEN/TS xxxx-2: 2019-out of-plane loaded glass components, CEN-European Committee for Standardization, Brussels, Belgium, 2019.

[3] K. Langosch, S. Dimova, A. V. Pinto et al., "Guidance for European structural design of glass components-support to the implementation, harmonization and further development of the eurocodes," in Report EUR 26439-Joint Research CentreInstitute for the Protection and Security of the Citizen, P. Dimova and D. Feldmann, Eds., European Union, Luxembourg City, Luxembourg, 2014.

[4] CNR-DT 210/2013, Istruzioni per la Progettazione. l'Esecuzione ed il Controllo di Costruzioni con Elementi Strutturali in Vetro (Guideline for Design, Execution and Control of Constructions Made of Structural Glass Elements (in Italian)), National Research Council (CNR), Rome, Italy, 2013.

[5] Buildings Department, "Code of practice for the structural use of glass," 2018, http://www.bd.gov.hk./.

[6] A. I. S Glass, "Code of practice for use of glass in buildings," December 2020, https://www.aisglass.com/sites/default/files/ pdfs/technical\%20papers/AIS-59.pdf.

[7] J. Blaauwendraad, "Buckling of laminated glass columns," Heron-English Edition, vol. 52, no. 1-2, p. 147, 2007.

[8] M. Feldmann and K. Langosch, "Buckling resistance and buckling curves of pane-like glass columns with monolithic sections of heat strengthened and tempered glass," Challenging Glass Conference Proceedings, vol. 2, pp. 319-330, 2010.

[9] P. Foraboschi, "Buckling of a laminated glass column under test," Structural Engineer, vol. 87, no. 1, pp. 2-8, 2009.

[10] S. Aiello, G. Campione, G. Minafò, and N. Scibilia, "Compressive behaviour of laminated structural glass members," Engineering Structures, vol. 33, no. 12, pp. 3402-3408, 2011.

[11] C. Amadio and C. Bedon, "Buckling of laminated glass elements in compression," Journal of Structural Engineering, vol. 137, no. 8, 2011.

[12] O. Pešek and J. Melcher, "Lateral-torsional buckling of laminated structural glass beams," Procedia Engineering, vol. 190, pp. 70-77, 2017.

[13] L. Valarihno, J. R. Correia, M. Machado-e-Costa, F. A. Branco, and N. Silvestre, "Lateral-torsional buckling behaviour of long-span laminated glass beams: analytical, experimental and numerical study," Materials and Design, vol. 102, pp. 264-275, 2016.

[14] C. Amadio and C. Bedon, "Buckling of laminated glass elements in out-of-plane bending," Engineering Structures, vol. 32 , no. 11 , pp. 3780-3788, 2010.

[15] J. Belis, C. Bedon, C. Louter, C. Amadio, and R. Van Impe, "Experimental and analytical assessment of lateral torsional buckling of laminated glass beams," Engineering Structures, vol. 51, pp. 295-305, 2013.

[16] C. Amadio and C. Bedon, "A buckling verification approach for monolithic and laminated glass elements under combined in-plane compression and bending," Engineering Structures, vol. 52, pp. 220-229, 2013.

[17] C. Bedon and C. Amadio, "Flexural-torsional buckling: experimental analysis of laminated glass elements," Engineering Structures, vol. 73, no. 8, pp. 85-99, 2014. 
[18] A. Luible and M. Crisinel, "Buckling strength of glass elements in compression," Structural Engineering International, vol. 14, no. 2, pp. 120-125, 2004.

[19] D. Mocibob, "Glass panels under shear loading-use of glass envelopes in building stabilization," Ph.D. thesis no. 4185, EPFL Lausanne, Lausanne, Switzerland, 2008.

[20] C. Bedon and C. Amadio, "Buckling analysis of simply supported flat glass panels subjected to combined in-plane uniaxial compressive and edgewise shear loads," Engineering Structures, vol. 59, pp. 127-140, 2014.

[21] C. Bedon and C. Amadio, "Design buckling curves for glass columns and beams," Proceedings of the Institution of Civil Engineers-Structures and Buildings, vol. 168, no. 7, pp. 514-526, 2015.

[22] C. Bedon and C. Amadio, "A unified approach for the shear buckling design of structural glass walls with non-ideal restraints," American Journal of Engineering and Applied Sciences, vol. 9, no. 1, pp. 64-78, 2016.

[23] G. D’Ambrosio and L. Galuppi, "Enhanced effective thickness model for buckling of LG beams with different boundary conditions," Glass Struct. Eng.vol. 5, pp. 205-210, 2020.

[24] L. Galuppi and G. Royer-Carfagni, "Enhanced Effective Thickness for laminated glass beams and plates under torsion," Engineering Structures, vol. 206, p. 110077, 2020.

[25] M. Momeni and C. Bedon, "Uncertainty assessment for the buckling analysis of glass columns with random parameters," International Journal of Structural Glass and Advanced Materials Research, vol. 4, no. 1, pp. 254-275, 2020.

[26] EN 572-2:2004, Glass in Buildings-Basic Soda Lime Silicate Glass Products, CEN, Brussels, Belgium, 2004.

[27] Simulia, ABAQUS v.6.14 Computer Software and Online Documentation, Dassault Systèmes, Vélizy-Villacoublay, France, 2020.

[28] J. Belis, R. V. Impe, G. Lagae, and W. Vanlaere, "Enhancement of the buckling strength of glass beams by means of lateral restraints," Structural Engineering and Mechanics, vol. 15, no. 5, pp. 495-511, 2003.

[29] E. Verhoeven, "Effect van constructieve kitvoegen op de stabiliteit van glazen liggers (in Dutch)," Master thesis, LMOLaboratory for Research on Structural Models, Ghent University, Ghent, Belgium, 2008.

[30] D. Sonck and J. Belis, "Elastic lateral-torsional buckling of glass beams with continuous lateral restraints," Glass Structures \& Engineering, vol. 1, no. 1, pp. 173-194, 2016.

[31] C. Bedon, J. Belis, and C. Amadio, "Structural assessment and lateral-torsional buckling design of glass beams restrained by continuous sealant joints," Engineering Structures, vol. 102, pp. 214-229, 2015.

[32] C. Bedon and C. Amadio, "Analytical and numerical assessment of the strengthening effect of structural sealant joints for the prediction of the LTB critical moment in laterally restrained glass beams," Materials and Structures, vol. 49, no. 6, pp. 2471-2492, 2015.

[33] D. Santo, S. Mattei, and C. Bedon, "Elastic critical moment for the lateral-torsional buckling (LTB) analysis of structural glass beams with discrete mechanical lateral restraints," Material, vol. 13 , no. 11, p. 2492, 2020.

[34] A. Luible and D. Schärer, "Lateral torsional buckling of glass beams with continuous lateral support," Glass Structures \& Engineering, vol. 1, no. 1, pp. 153-171, 2016.

[35] X.-T. Chu, R. Kettle, and L.-Y. Li, "Lateral-torsion buckling analysis of partial-laterally restrained thin-walled channelsection beams," Journal of Constructional Steel Research, vol. 60, no. 8, pp. 1159-1175, 2004.
[36] R. H. J. Bruins RHJ, "Lateral-torsional buckling of laterally restrained steel beams," Report nr A-2007-7, Technische Universiteit Eindhoven, Eindhoven, The Netherlands, 2007.

[37] X.-T. Chu, J. Rickard, and L.-Y. Li, "Influence of lateral restraint on lateral-torsional buckling of cold-formed steel purlins," Thin-Walled Structures, vol. 43, no. 5, pp. 800-810, 2005.

[38] A. Taras and R. Greiner, "Torsional and flexural torsional buckling - a study on laterally restrained I-sections," Journal of Constructional Steel Research, vol. 64, no. 8, pp. 725-731, 2008.

[39] A. Khelil and B. Larue, "Simple solutions for the flexuraltorsional buckling of laterally restrained I-beams," Engineering Structures, vol. 30, no. 10, pp. 2923-2934, 2008.

[40] B. Larue, A. Khelil, and M. Gueury, "Elastic flexural-torsional buckling of steel beams with rigid and continuous lateral restraints," Journal of Constructional Steel Research, vol. 63, pp. 692-708, 2006.

[41] B. Larue, A. Khelil, and M. Gueury, "Evaluation of the lateraltorsional buckling of an I beam section continuously restrained along a flange by studying the buckling of an isolated equivalent profile," Thin-Walled Structures, vol. 45, no. 1, pp. 77-95, 2007.

[42] C. Bedon, J. Belis, and A. Luible, "Assessment of existing analytical models for the lateral torsional buckling analysis of PVB and SG laminated glass beams via viscoelastic simulations and experiments," Engineering Structures, vol. 60, no. 2, pp. 52-67, 2014. 